\title{
Mixed-Mode Interlaminar Fracture Toughness of Glass and Carbon Fibre Powder Epoxy Composites-For Design of Wind and Tidal Turbine Blades
}

\author{
Christophe Floreani ${ }^{1, *}$, Colin Robert ${ }^{1}\left(\mathbb{D}\right.$, Parvez Alam $^{1}\left(\mathbb{D}\right.$, Peter Davies $^{2}(\mathbb{D})$ and Conchúr M. Ó Brádaigh ${ }^{1}(\mathbb{D}$ \\ 1 School of Engineering, Institute for Materials and Processes, The University of Edinburgh, \\ Edinburgh EH9 3FB, UK; colin.robert@ed.ac.uk (C.R.); parvez.alam@ed.ac.uk (P.A.); \\ c.obradaigh@ed.ac.uk (C.M.ÓB.) \\ 2 Ifremer, Marine Structures Laboratory, 29280 Plouzané, France; peter.davies@ifremer.fr \\ * Correspondence: christophe.floreani@ed.ac.uk
}

Citation: Floreani, C.; Robert, C.; Alam, P.; Davies, P.; Ó Brádaigh, C.M. Mixed-Mode Interlaminar Fracture Toughness of Glass and Carbon Fibre Powder Epoxy Composites-For Design of Wind and Tidal Turbine Blades. Materials 2021, 14, 2103. https://doi.org/10.3390/ma14092103

Academic Editor: Milad Saeedifar

Received: 25 March 2021

Accepted: 16 April 2021

Published: 21 April 2021

Publisher's Note: MDPI stays neutral with regard to jurisdictional claims in published maps and institutional affiliations.

Copyright: (C) 2021 by the authors. Licensee MDPI, Basel, Switzerland. This article is an open access article distributed under the terms and conditions of the Creative Commons Attribution (CC BY) license (https:/ / creativecommons.org/licenses/by/ $4.0 /)$.

\begin{abstract}
Powder epoxy composites have several advantages for the processing of large composite structures, including low exotherm, viscosity and material cost, as well as the ability to carry out separate melting and curing operations. This work studies the mode I and mixed-mode toughness, as well as the in-plane mechanical properties of unidirectional stitched glass and carbon fibre reinforced powder epoxy composites. The interlaminar fracture toughness is studied in pure mode I by performing Double Cantilever Beam tests and at $25 \%$ mode II, 50\% mode II and $75 \%$ mode II by performing Mixed Mode Bending testing according to the ASTM D5528-13 test standard. The tensile and compressive properties are comparable to that of standard epoxy composites but both the mode I and mixed-mode toughness are shown to be significantly higher than that of other epoxy composites, even when comparing to toughened epoxies. The mixed-mode critical strain energy release rate as a function of the delamination mode ratio is also provided. This paper highlights the potential for powder epoxy composites in the manufacturing of structures where there is a risk of delamination.
\end{abstract}

Keywords: toughened composites; fracture toughness; delamination

\section{Introduction}

Fibre reinforced polymer composites have very good in-plane mechanical properties in the fibre direction. Laminated composites have no through-thickness reinforcement, however, and are therefore subject to the risk of delamination, one of the lowest energy modes of failure [1], making it one of the main causes of concern in composite structures exposed to fatigue loads such as wind and tidal turbine blades. Delamination can also occur in composite structures exposed to high interlaminar stresses. The causes of delamination can be grouped into three main categories [2]: (i) delamination from out-of-plane loading, such as in joints or because of impact loads, (ii) the loading of curved composites which creates out-of-plane stresses and delaminations, and (iii) delamination originating from material discontinuities such as ply drops, holes, or free edges. The study and prediction of delamination in both static and fatigue loading is an active topic of research and has been the subject of numerous publications in recent years [3-5]. Preventing delamination is critical to the integrity of a composite structure as its presence drastically reduces its load bearing capabilities [6] and it is difficult to detect [7].

There are three modes of delamination: (i) mode I is the normal crack opening mode, (ii) mode II is in-plane shear delamination along the fibre direction and (iii) mode III is the out-of-plane shear delamination. In most structures, delamination will occur in mixedmode with combined normal and shear crack propagation. For example, in a wind turbine blade, delamination may occur through a combination of mode II delamination generated by the bending stresses in tension and compression as well as mode I fracture due to the curvature of the deformed blade leading to out-of-plane loading. The rate of delamination 
in laminated composites is governed by the Strain Energy Release Rate (SERR), defined as the strain energy released per crack surface area as it propagates. It is therefore crucial to select materials with a high toughness for structures which may be exposed to delamination. One option is to use advanced thermoplastic matrices such as Polyetheretherketone (PEEK) or Polyetherketoneketone (PEKK), but due to cost constraints, it is not always economical to produce large structures from these high performance materials. Very large composite structures, such as wind and tidal turbine blades, typically contain numerous ply drops which exacerbate the risk of delamination. Engineering thermoplastic matrices such as Nylon (PA) and Polybutylene terephthalate (PBT) could be considered for these large structures, but their viscosities are typically too high to achieve good consolidation under the vacuum-only processing conditions involved. Recent work in the use of low viscosity, in-situ polymerised thermoplastics such as acrylics have opened the field of manufacture of room-temperature infused large structures from thermoplastic composites $[8,9]$, though there are still fundamental materials and manufacturing issues to be overcome.

The idea of manufacturing composites using powder polymers has been studied since the 1970s [10]. In the following decades, the use of both thermoplastic and thermoset powder resins to produce composite tape [11-13] were studied. In recent years, a powder epoxy resin has been developed for the manufacturing of large out-of-autoclave composite structures, focusing initially on the production of wind turbine blades, using oven heating or electrically heated ceramic tooling $[14,15]$. Recent work has shown that this resin has a low minimal viscosity [16] enabling good fabric impregnation and the manufacturing of structures with low porosity. It also produces a very low exothermic reaction with an enthalpy of 140 to $180 \mathrm{~J} / \mathrm{g}$ compared to 300 to $500 \mathrm{~J} / \mathrm{g}$ for conventional epoxy resins [16]. A subsequent study using resin flow and heat transfer models to study degree of cure and temperature profile during the manufacturing of a 100-ply thick laminate showed the potential of this powder epoxy for reducing the thermal runaway caused by the exothermic reaction $[17,18]$. The processing of powder epoxy composites also produces little to no volatile organic compounds, reducing the potential harm to humans and the environment and it is thermally stable, which means it can be stored at room temperature for long periods of time. Finally, the powder epoxy resin melts around $45^{\circ} \mathrm{C}$ while curing only starts around $140{ }^{\circ} \mathrm{C}[16]$. This allows for separation of the melting and curing phases, enabling the individual sections of structures such as turbine blades (e.g., skins and shear webs) to be formed and consolidated separately, assembled and then co-cured in a one-shot process without the need for adhesives [14]. All these properties make powder epoxy a good candidate for the manufacturing of large composite structures. Recent work involving the manufacturing and testing of a $6 \mathrm{~m}$ torsion box demonstrator from powder epoxy composites showed that large complex structures can be manufactured with good quality using this resin system [19].

Most of the work related to powder epoxy composites has focused on manufacturing properties and there are fewer data on their mechanical properties. A study on the development of an automated towpregging line using carbon and basalt fibre reinforced powder epoxy showed that the $0^{\circ}$ tensile properties of the carbon samples were similar to those published by the fibre manufacturers for standard epoxies [20]. The study also included tension, compression and flexural tests performed at $0^{\circ}$ and $90^{\circ}$ for the basalt fibre powder epoxy composites which showed that, despite a slightly lower $0^{\circ}$ compression strength, the rest of the measured properties were comparable to those of standard epoxies. Another study focused on the influence of fibre straightness and fibre sizing on the mechanical properties of powder epoxy composites [21,22]. This study also included $0^{\circ}$ tensile testing as well as $0^{\circ}$ and $90^{\circ}$ flexural testing. It showed that the powder epoxy reinforced carbon composites performed very well in tension in the longitudinal direction but were found to have a $25 \%$ lower $0^{\circ}$ flexural strength compared to data published by the fibre manufacturer. This was attributed to a lower longitudinal compression strength than that of standard epoxy composites. The mode I interlaminar fracture toughness was also determined using a Double Cantilever Beam (DCB) test. The values ranged from $1120 \mathrm{~J} / \mathrm{m}^{2}$ 
to $1610 \mathrm{~J} / \mathrm{m}^{2}$ at propagation and $950 \mathrm{~J} / \mathrm{m}^{2}$ to $1300 \mathrm{~J} / \mathrm{m}^{2}$ at initiation, depending on the fibre sizing used. However, no complete study of the mechanical properties of powder epoxy composites manufactured using fabrics has been published. As wind and tidal turbine blades are manufactured using fabric reinforcements, it is essential to obtain their mechanical properties. Additionally, the mixed-mode toughness properties of powder epoxy composites have not been previously investigated.

The aim of this work is to determine the in-plane mechanical properties of unidirectional glass and carbon fibre reinforced powder epoxy composites in tension and compression, as well as their toughness under mode I and mixed-mode loading. This will serve as the basis for the comparison of the mechanical properties of powder epoxy composites with those of standard epoxy composites and assess their potential as a material of choice in areas exposed to high risks of delamination. This work also discusses the differences in the observed behaviour between the carbon and glass composites studied, followed by fractography of the Mixed-Mode Bending (MMB) fracture surfaces using a Scanning Electron Microscope (SEM). Finally, the SERR as a function of mode ratio is measured for both the CFRP and GFRP powder epoxy composites using the Benzeggagh-Kenane and Power Law delamination criteria.

\section{Experimental Procedure}

\subsection{Material Manufacture and Preparation}

Fabrics which are readily available in the market are more likely to be suitable for the manufacturing of wind and tidal turbine blades in the near future than the specialised fabrics often studied in research projects. Fabrics used in this study were therefore limited to typical styles and weights used commercially in wind turbine blade production and were purchased from SAERTEX ${ }^{\circledR}$ (SAERTEX GmbH \& Co. KG, Saerbeck, Germany). To avoid issues with unstable crack growth following the weave pattern and hence deviating from single mode delamination characteristics of woven or multi-directional laminates [23], it was decided to work with unidirectional (UD) stitched fabrics, as a first step towards characterisation of the interlaminar fracture toughness properties of fibre reinforced powder epoxy composites. Hence, the following fabrics were studied: (i) a UD stitched carbon fabric (U-C-603 g/ $\mathrm{m}^{2}-1230 \mathrm{~mm}$ ) with $581 \mathrm{~g} / \mathrm{m}^{2}$ Zoltek (ZOLTEK Corporation, Bridgeton, MT, USA) Panex 35-13 $50 \mathrm{~K} 0^{\circ}$ fibres, $16 \mathrm{~g} / \mathrm{m}^{2} \pm 60^{\circ}$ E-glass fibres and $6 \mathrm{~g} / \mathrm{m}^{2}$ polyester stitching [24]; and (ii) a UD stitched glass fabric (U-E-591 g/m²-1200 mm) with $520 \mathrm{~g} / \mathrm{m}^{2}$ E-glass 1.200 Tex fibres, $54 \mathrm{~g} / \mathrm{m}^{2} 90^{\circ}$ E-glass fibres and $17 \mathrm{~g} / \mathrm{m}^{2}$ polyester stitching [25].

The formulation of the powder epoxy resin is proprietary and was not made available to the authors. It was designed by Swiss CMT AG and manufactured by Freilacke, Ltd. (Bräunlingen, Baden-Württemberg, Germany) who supplied the resin used in this work.

As powder epoxy possesses a low minimum viscosity (prior to gelation), it has a tendency to bleed out from the UD composite during the curing stage, which can lead to a high variation in the fibre volume fraction (FVF) of the final parts, making it difficult to manufacture plates at a specific FVF. To avoid this, a frame with inner dimensions of $300 \mathrm{~mm} \times 280 \mathrm{~mm}$ was manufactured as shown in Figure 1, from an $8 \mathrm{~mm}$ thick stainlesssteel plate. Two stainless steel caul plates were used in the process with the top one designed to have a tight fit into the frame, ensuring that uniform pressure was exerted by the applied vacuum, as well as limiting the resin bleed-out. To ensure easy removal of the plates, the caul plates were covered in TFG 250 PTFE (Tygavac Advanced Materials Ltd., Oldham, UK) coated glass fibre and thin TF 050AH PTFE (Tygavac, Oldham, UK) tape was applied to the frame. Powder epoxy was sprinkled evenly before the first ply and subsequently between each ply. The weight of powder epoxy was calculated using the resin and fabric densities to lead to a 50\% FVF for the finished plates and was evenly distributed between the plies. This process ensured a good fibre wetting and an even resin distribution. Once the layup was complete, the system was vacuum bagged and cured in an oven. As the powdered resin was stored in the laboratory at room temperature for several months, it was susceptible to humidity absorption. Therefore, the first step of the laminate curing 
cycle involved drying by exposing the laminate to a $50{ }^{\circ} \mathrm{C}$ temperature environment for $8 \mathrm{~h}$. This stage also lowers the viscosity of the resin as it starts to sinter and melt around this temperature allowing for good fibre impregnation. This was followed by $2 \mathrm{~h}$ of curing at $135{ }^{\circ} \mathrm{C}$, followed by two hours of post-cure at $185^{\circ} \mathrm{C}$. A dynamic mechanical thermal analysis was conducted on the neat powder epoxy resin on a Tritec 2000 machine produced by Triton Technology (Keyworth, UK). The cured resin was shown to have a Tg onset of $105.5^{\circ} \mathrm{C}$ and a $\mathrm{Tg}$ defined as the peak of the $\tan (\delta)$ curve of $125.6^{\circ} \mathrm{C}$.

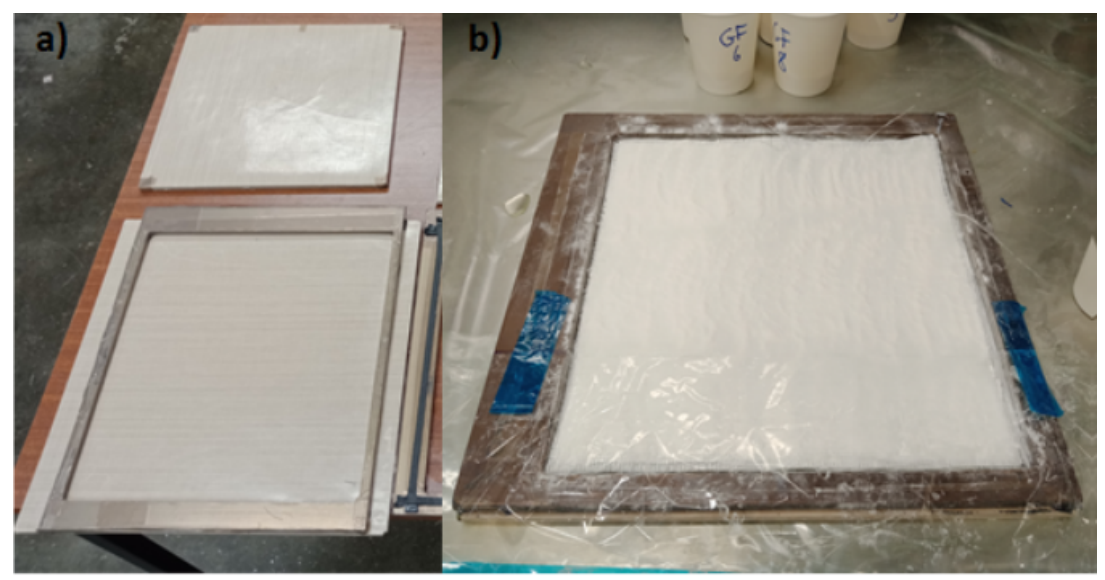

Figure 1. Frame designed for manufacturing fibre reinforced epoxy plates (a) before layup (b) during DCB plate manufacturing.

\subsection{Tensile Testing}

The tensile tests were performed according to BS EN ISO 527 [26] using $0^{\circ}, 90^{\circ}$ and $\pm 45^{\circ}$ coupons. The samples were machined using a Benetec ${ }^{\circledR}$ (Barnstaple, UK) diamond coated wet saw to a length of $250 \mathrm{~mm}$ and a width of $25 \mathrm{~mm}$. Five coupons were extracted for each test as required by the standard. The test was performed using an MTS Systems Corporation (Eden Prairie, MN, USA) Criterion C45 Universal Test Machine using a crosshead displacement of $2 \mathrm{~mm} / \mathrm{min}$ and a $300 \mathrm{kN}$ load cell. Glass fibre end tabs were bonded to the specimens to limit stress concentrations at the grips of the MTS machine. Paint was speckled on the coupons to allow for strain measurement with an Imetrum $^{\mathrm{TM}}$ (Bristol, UK) Video Extensometer.

The stiffness and Poisson's ratio were determined over a strain range of $0.05 \%$ to $0.25 \%$. The shear modulus was calculated from the $\pm 45^{\circ}$ samples using Equation (1) [27]:

$$
G_{12}=\frac{E_{x}}{2\left(1+v_{x y}\right)}
$$

where: $G_{12}$ is the material shear modulus, $E_{x}$ is the stiffness in the global x-direction corresponding to the $0^{\circ}$ direction in this case and $v_{x y}$ is the Poisson's ratio in the global coordinates.

\subsection{Compression Testing}

Compression testing was carried out according to ASTM D6641 [28] which allows the determination of the compressive strength and stiffness of fibre reinforced composites using a Combined Loading Compression (CLC) fixture. Five $0^{\circ}$ and $90^{\circ}$ samples with a width of $13 \mathrm{~mm}$ and length of $140 \mathrm{~mm}$ were extracted from the four-ply CFRP and six-ply thick GFRP plates. The coupons were tested untabbed using a CLC fixture manufactured by Wyoming Test Fixtures (Salt Lake City, UT, USA) shown in Figure 2, an MTS Criterion C45 Universal Test Machine with a crosshead displacement of $1.3 \mathrm{~mm} / \mathrm{min}$ and a $300 \mathrm{kN}$ load cell. Paint was also speckled on the compression samples to allow for strain measurement using the Imetrum ${ }^{\mathrm{TM}}$ video extensometer. 


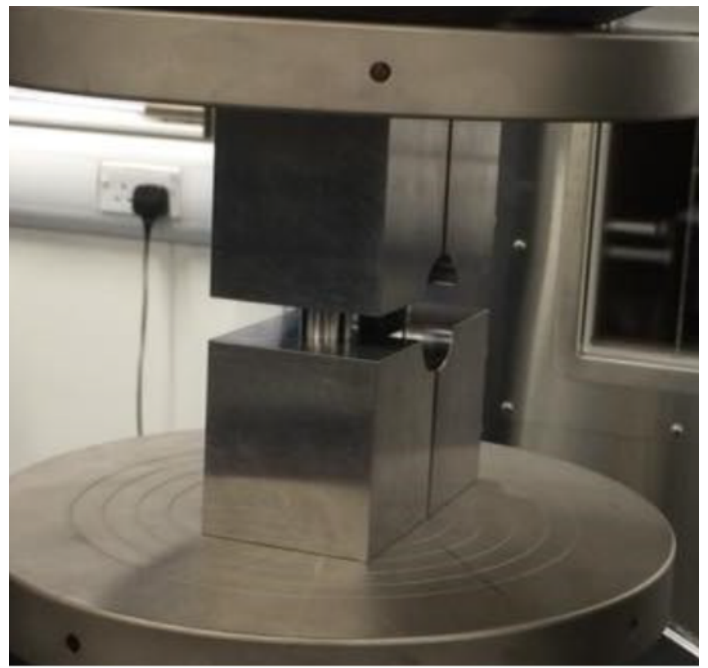

Figure 2. Compression Testing According to ASTM D6641.

\subsection{Mode I Interlaminar Fracture Toughness}

A Double Cantilever Beam (DCB) test was conducted on the CFRP samples following ASTM D5528-13 [29]. This allowed the measurement of the critical mode I strain energy release rate during crack initiation $\left(G_{i c}\right)$ and propagation $\left(G_{I C}\right)$. The test was conducted on a 3369 series Instron $^{\circledR}$ (High Wycombe, UK) $50 \mathrm{kN}$ Universal Test Machine equipped with a $1 \mathrm{kN}$ load cell. Stainless steel loading blocks were bonded to the ends of the composite using VTFA 400 adhesive and a $1 \mathrm{~mm} / \mathrm{min}$ constant crosshead displacement was applied. The CFRP plates were manufactured with six plies giving an average specimen thickness of $3.52 \mathrm{~mm}$, while the GFRP plates were manufactured with eight plies for an average specimen thickness of $3.47 \mathrm{~mm}$. A $60 \mathrm{~mm}$ long, 13- $\mu \mathrm{m}$ thick Teflon (PTFE) film was inserted in the middle of the plate during manufacture as shown in Figure 1b). White paint was applied to the side of the specimen as seen in Figure 3, on which a random pattern of black dots was added. This allowed the Manta G-146B/G-146C camera (Allied Vision Technologies $\mathrm{GmbH}$, Stadtroda, Germany) and the Imetrum video extensometer to record the crack extension in real time. Considering that the loading blocks were $25 \mathrm{~mm}$ in length, the DCB samples had an initial crack length around $47.5 \mathrm{~mm}$. The initial crack length was measured at the end of each test to obtain the precise value needed for the $G_{I C}$ calculations.

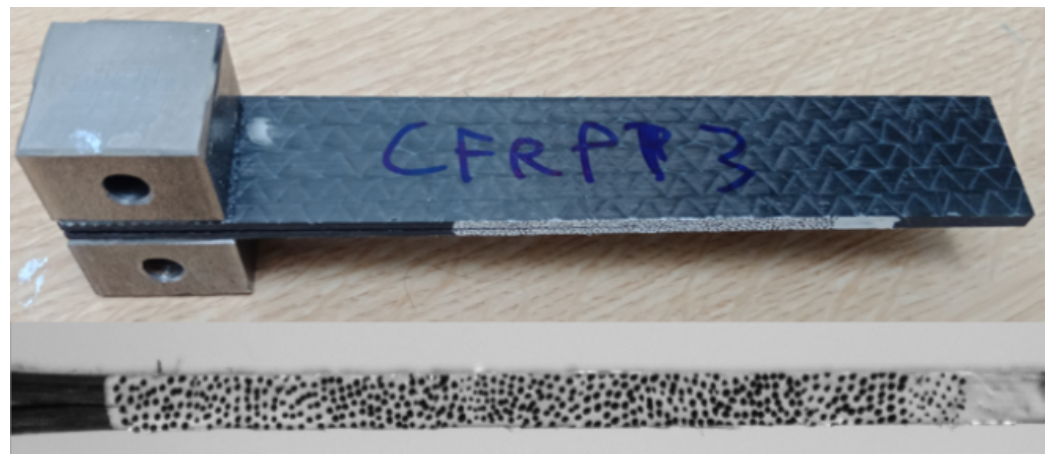

Figure 3. Specimen manufactured for double cantilever beam testing.

Using the Modified Beam Theory (MBT) method, the $G_{I C}$ can be calculated given by the following equation [29]:

$$
G_{I C}=\frac{3 P \delta}{2 b(a+|\Delta|)} \cdot \frac{F}{N}
$$

where $P$ and $\delta$ are respectively the load applied and displacement at the loading blocks, $b$ is the specimen width, $a$ is the crack length and $|\Delta|$ is a correction factor which can be determined by plotting the linear best fit of the cube root of the compliance against the 
crack length and calculating the root of this function. The MBT method uses this correction factor to artificially increase the delamination length used in the $G_{I C}$ calculation. It accounts for the rotation of the crack front. $F$ is a large displacement correction factor and $N$ is a loading block correction factor. Equations to calculate $F$ and $N$ are defined in the ASTM D5528-13 [29] test standard.

Results for critical strain energy release rate $\left(G_{I C}\right)$ are reported both at the point of fracture initiation and crack propagation as recommended in the ASTM D5528-13 test standard. Three different definitions were proposed for the point of fracture initiation from the starter film (with no pre-crack): (i) the location in the load-displacement curve where there was a deviation from linearity (referred to as NL in this paper); (ii) the point at which delamination growth was observed visually; (iii) the point at which the compliance of the specimen increased by $5 \%$ (referred to as $5 \%$ compliance in this paper). In this work, the initiation $G_{I C}$ values were reported using the NL point and the 5\% compliance point. The propagation $G_{I C}$ was defined as the mean of the R-curve values from the $5 \%$ compliance point until the end of the test.

\subsection{Mixed Mode Interlaminar Fracture Toughness}

Mixed-Mode Bending (MMB) tests were carried out according to ASTM D6671 [30]. To obtain enough points to obtain a critical strain energy release rate curve as a function of the mode ratio $(\phi)$, defined as the ratio of mode II strain energy release rate over the total SERR, it was decided to perform three sets of tests: $25 \%$ mode II, 50\% mode II and 75\% mode II. These three ratios were selected to ensure that the critical SERR was measured at evenly spaced points between $0 \%$ and $75 \%$ mode ratio. This will allow for good curve fitting of the critical SERR as a function of the mode ratio. The mode ratios $(\phi)$ were adjusted by adjusting the distance between the load application and the centre of the specimen span as shown Figure 4. In Figure 4a) the load is applied close to the centre of the $120 \mathrm{~mm}$ span which represents the $25 \%$ mode II while in Figure $4 \mathrm{~b}$ ) the load is applied much further from the centre of the span and was captured from the 75\% mode II test. The further the load was applied from the centre of the MMB sample, the higher the percentage of mode I delamination was applied.
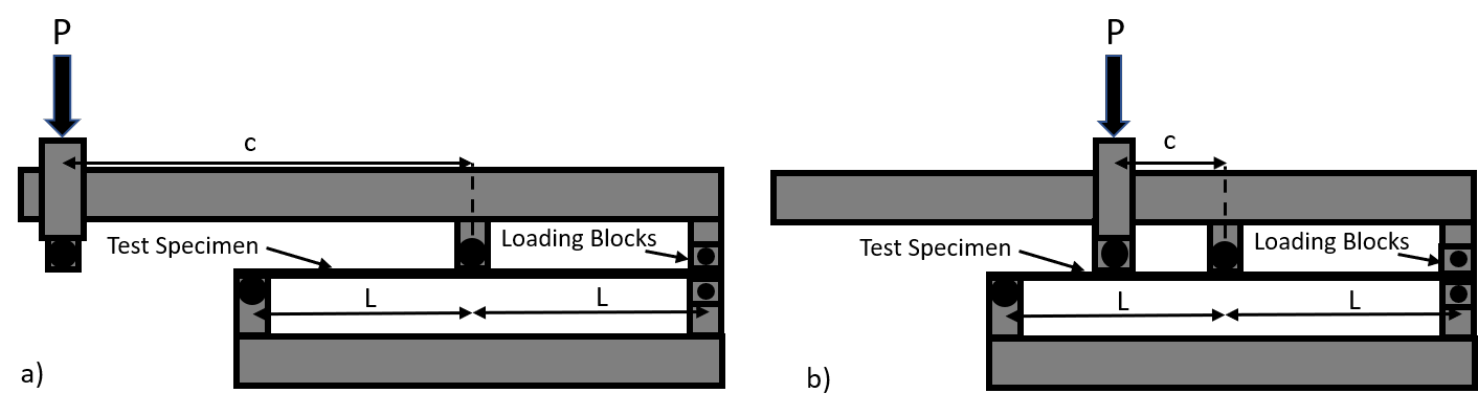

Figure 4. MMB test fixture showing (a) 25\% Mode II and (b) 75\% Mode II.

The distance from the point of load application to the centre of the sample span(c) is defined in the ASTM D6671 [30] test standard as:

$$
c=\frac{12 \beta^{2}+3 \alpha+8 \beta \sqrt{3 \alpha}}{36 \beta^{2}-3 \alpha}
$$

where:

$$
\begin{gathered}
\alpha=\frac{1-\phi}{\phi} \\
\beta=\frac{a+\chi h}{a+0.42 \chi h}
\end{gathered}
$$


where $a$ is the initial crack length, $\phi$ is the mode ratio and $\chi$ is the crack length correction parameter defined as [30]:

$$
\chi=\sqrt{\frac{E_{11}}{11 G_{13}}\left(3-2\left(\frac{\Gamma}{1+\Gamma}\right)^{2}\right)}
$$

where $E_{11} G_{13}$ are the longitudinal stiffness and out of plane shear modulus of the sample and $\Gamma$ is the transverse modulus correction parameter defined as [30]:

$$
\Gamma=\frac{1.18 \sqrt{E_{11} E_{22}}}{G_{13}}
$$

Five samples were extracted from the CFRP and GFRP plates for each test. To maximise the length of crack propagation, the samples were cut to a length of $180 \mathrm{~mm}$ so that a $120 \mathrm{~mm}$ span length could be used for the MMB test. The same stainless steel loading blocks used during the DCB tests were bonded on the MMB samples. Considering the initial crack length of $47.5 \mathrm{~mm}$ this ensured that each sample had around $12.5 \mathrm{~mm}$ of crack propagation. This allowed the SERR to stabilise during the test so that both initiation and propagation $G_{c}$ values could be measured. The geometry of the MMB test fixture made it difficult to use a video extensometer to track the crack propagation. Therefore, graph paper was instead glued at the bottom of each sample and a picture was captured each second with a camera to allow for manual measurement of crack length throughout the test. The load and crosshead displacements were measured using a 3369 series Instron ${ }^{\circledR}$ (High Wycombe, Buckinghamshire, UK) $50 \mathrm{kN}$ Universal Test Machine, equipped with a $10 \mathrm{kN}$ load cell. A crosshead displacement of $2 \mathrm{~mm} / \mathrm{min}$ was applied to the samples. The test setup is shown in Figure 5. The SERR can be calculated throughout the test using the following equations [30]:

$$
\begin{gathered}
G_{I}=\frac{12 P^{2}(3 c-L)^{2}}{16 b^{2} h^{3} L^{2} E_{1 f}}(a+\chi h) \\
G_{I I}=\frac{9 P^{2}(c+L)^{2}}{16 b^{2} h^{3} L^{2} E_{1 f}}(a+0.42 \chi h)
\end{gathered}
$$

where $P$ is the applied load, $c$ is the distance between the point of load application and the centre of the specimen span, $L$ is the half-span of the specimen, $a$ is the measured crack length, $h$ is the sample half-thickness, $b$ is the sample width and $E_{1 f}$ is the flexural stiffness in the longitudinal direction estimated from the linear region of the MMB forcedisplacement curves. The method for obtaining an estimate of $E_{1 f}$ is described in the ASTM D6671 test standard [30]. For the MMB test, the reported $G_{c}$ values were defined in a similar way to the DCB test with the initiation $G_{c}$ defined at both the point of non-linearity (NL) and at the $5 \%$ increase in compliance point. The propagation $G_{c}$ values were also defined as the mean of the R-curve from the $5 \%$ increase in compliance point until the end of the test. However, the shape of the samples used in the MMB test allowed for a stable crack propagation of only $12.5 \mathrm{~mm}$. Therefore, to perform a fair comparison between the mode I and mixed-mode critical strain energy release rates in Section 4.3, propagation values from the mode I test were limited to data from the first $12.5 \mathrm{~mm}$ of crack growth only. Finally, using the DCB and MMB test results, the SERR was plotted as a function of the mode ratio for the $0 \%, 25 \%, 50 \%$ and $75 \%$ mode II. The aim of this test is to perform a curve fitting to obtain an estimate of the critical SERR for any mode ratio, as required for a mixed mode delamination finite element model. The data points were fitted using two widely used methods for estimating the mixed-mode SERR: (i) the Power Law criterion [31] and (ii) the Benzeggagh-Kenane (B-K) equation [32]. When mode III delamination can be neglected, the Power Law is defined as [31]:

$$
\left(\frac{G_{I}}{G_{I C}}\right)^{\alpha}+\left(\frac{G_{I I}}{G_{I I C}}\right)^{\alpha}=1
$$



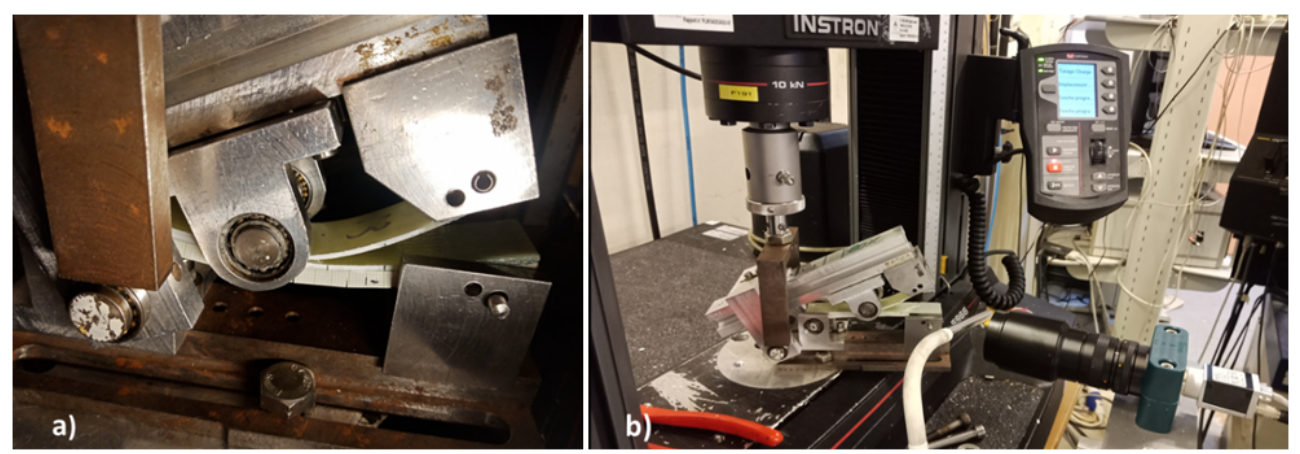

Figure 5. MMB test fixture. (a) Closeup of test fixture (b) Full MMB setup with instron test machine and camera.

The critical strain energy release rate can be found using the following equation:

$$
\left[\left(\frac{1-\phi}{G_{I C}}\right)^{\alpha}+\left(\frac{\phi}{G_{I I C}}\right)^{\alpha}\right]^{-1 / \alpha}=G_{C}
$$

where $\phi$ is the mode ratio defined as the ratio of mode II SERR divided by the total SERR.

The Benzeggagh-Kenane equation is defined as follows [32]:

$$
G_{I C}+\left(G_{I I C}-G_{I C}\right) \phi^{n}=G_{C}
$$

where $G_{I C}$ and $G_{I I C}$ are defined as the critical mode I and mode II SERR respectively and $\phi$ is the mode ratio.

\subsection{Manufacturing Quality Check}

The thickness of each plate tested was measured at 16 different points using a Kroeplin $^{\circledR}$ (Schlüchtern, Germany) thickness gauge to investigate the presence of defects or resin rich regions. The six-ply thick CFRP and eight-ply thick GFRP plates had an average thickness of $3.52 \mathrm{~mm}$ and $3.47 \mathrm{~mm}$ respectively, with measured standard deviations of $0.077 \mathrm{~mm}$ and $0.014 \mathrm{~mm}$ respectively. This suggests that the manufacturing process developed produced laminates of consistent thickness with only minor disparities within each plate.

A resin burn-off test according to ASTM D3171-15 [33] was performed to measure the Fibre Volume Fraction (FVF) of the CFRP and GFRP specimens. FVF measurements were taken for a total of six CFRP and GFRP samples. Despite an initial target of 50\% FVF, resin bleedout during manufacturing led to average measured FVF values for the CFRP and GFRP samples of $53.3 \%$ and $51.1 \%$ respectively. There was slightly more resin bleedout for the CFRP plates compared to the GFRP plates, which explains the higher FVF obtained.

Small $20 \mathrm{~mm}$ by $15 \mathrm{~mm}$ samples were cut in the transverse fibre direction. They were placed within an epoxy resin matrix, which was cured at room temperature for $24 \mathrm{~h}$, followed by $5 \mathrm{~h}$ of post-cure at $50 \mathrm{C}$. The samples were then polished on an automatic polishing machine using sandpaper with increasing grit size (P400, P800 and P1200). To ensure a very smooth surface for optical micrographs, the samples were polished using a diamond-based dispersion with a $3 \mu \mathrm{m}$ particle size. The laminates were then observed under a Zeiss optical microscope fitted with an AxioCam ${ }^{\mathrm{TM}}$ MRc 5 camera (Oberkochen, Germany). The fibres and resin were observed up to $50 \times$ zoom as shown in Figure 6 . The black marks around some of the fibres are machining marks which were not successfully removed by the polishing process. However, observations show that there were no visible macro voids in the samples studied. Indeed, these would appear as dark circular spots on Figure 6. Although a more precise imaging method such as a CT-scan would be required to confirm the exact void content, the results from the optical micrographs suggest that the void content is very low for these laminates. 


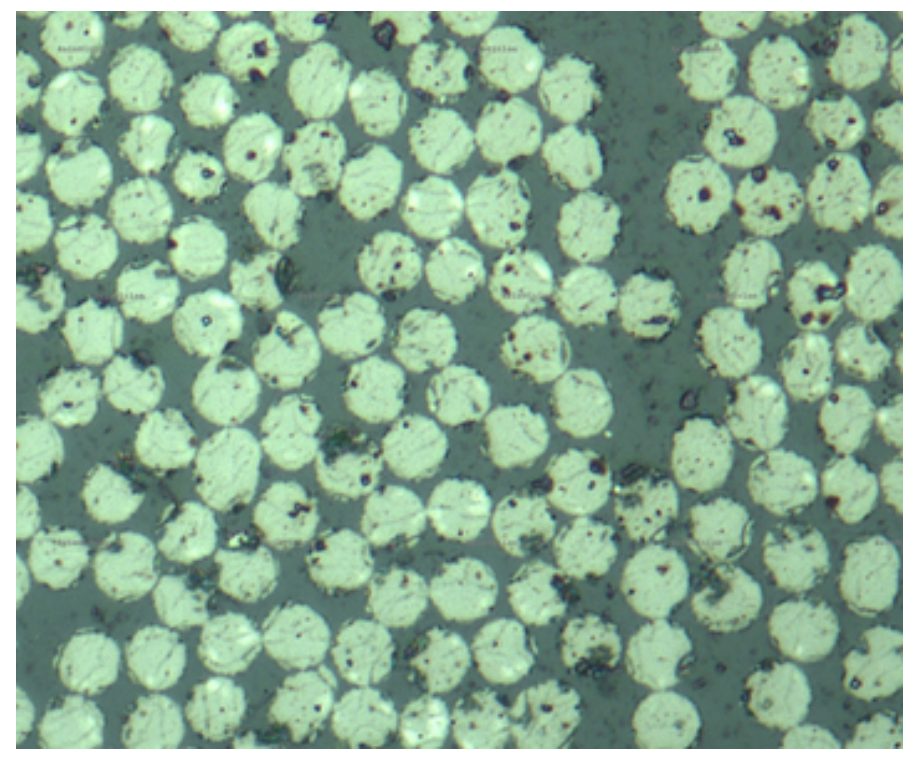

Figure 6. Optical microscope imageof CFRP sample at $50 \times$ zoom.

\section{Results}

\subsection{Tension Results}

Table 1 summarises the tensile test results for the carbon fibre and glass fibre powder epoxy specimens. The $0^{\circ} \mathrm{CFRP}$ coupons showed relatively high variability with a coefficient of variation (COV) of $13.7 \%$. Inspection of the failed samples showed that there were slight deviations in the fibre alignment within the CFRP plates. The use of a heavy $581 \mathrm{~g} / \mathrm{m}^{2}$ fabric and the presence of only $3 \%$ weight for the off-axis fibres and stitching meant the fibres were very loose during manufacturing, leading to occasional distortions in orientation prior to curing. On the other hand, the glass fibre tensile tests showed low coefficient of variations for all tests (all below 8.4\%) suggesting very good repeatability between the coupons. The presence of the $10 \%$ of $90^{\circ}$ fibres in the glass fabric explained the higher measured stiffness and strength in the transverse direction compared to the CFRP specimens.

Table 1. Summary of tensile test results.

\begin{tabular}{|c|c|c|c|c|c|c|}
\hline \multirow[b]{2}{*}{ Property } & \multicolumn{3}{|c|}{ GFRP } & \multicolumn{3}{|c|}{ CFRP } \\
\hline & Result & Standard Deviation & $\mathrm{COV}$ & Result & Standard Deviation & $\mathrm{COV}$ \\
\hline Longitudinal Modulus $\mathrm{E}_{1}(\mathrm{GPa})$ & 39.4 & 0.65 & $1.6 \%$ & 123.0 & 6.7 & $5.4 \%$ \\
\hline Longitudinal Strength $\sigma_{1}(\mathrm{MPa})$ & 993 & 37 & $3.7 \%$ & 1492 & 205 & $13.7 \%$ \\
\hline Transverse Modulus $E_{2}(\mathrm{GPa})$ & 13.7 & 0.77 & $5.6 \%$ & 8.47 & 0.37 & $4.4 \%$ \\
\hline Transverse Strength $\sigma_{2}(\mathrm{MPa})$ & 98.0 & 5.3 & $5.4 \%$ & 31.5 & 1.9 & $6.0 \%$ \\
\hline Shear Modulus $\mathrm{G}_{12}(\mathrm{GPa})$ & 3.91 & 0.33 & $8.4 \%$ & 4.30 & 0.67 & $15.6 \%$ \\
\hline Shear Strength $\tau_{12}(\mathrm{MPa})$ & 71.6 & 2.6 & $3.6 \%$ & 64.2 & 1.2 & $1.9 \%$ \\
\hline Poisson's Ratio v 12 & 0.29 & 0.093 & $32.1 \%$ & 0.36 & 0.086 & $23.9 \%$ \\
\hline
\end{tabular}

\subsection{Compression Results}

The results of the compression tests are summarised in Table 2. The glass fibre coupons showed reductions of $4.1 \%$ and $2.2 \%$ respectively for the longitudinal and transverse stiffness between the tension and compression tests. The reduction in stiffness between that measured in tension and in compression was far greater for the CFRP samples which showed drops of $18 \%$ and $20 \%$ respectively for the longitudinal and transverse stiffness. A notable reduction in the longitudinal strength was measured in compression compared to tension with a $48 \%$ and 59\% drop respectively for the GFRP and CFRP samples. On the other hand, an increase of $70 \%$ and $313 \%$ respectively was measured for the GFRP and 
CFRP transverse strength in compression compared to tension. The presence of the off-axis fibres in the GFRP fabric explain the lower increase in the transverse strength in compression compared to the CFRP samples as their tensile transverse strength was more than three times higher than that of CFRP. The variability between samples in the longitudinal direction during compression testing was slightly lower for the GFRP specimens compared to the CFRP, but the difference was much lower than in the tension tests.

Table 2. Summary of Compression Test Results.

\begin{tabular}{ccccccc}
\hline & \multicolumn{3}{c}{ GFRP } & \multicolumn{2}{c}{ CFRP } \\
\hline Property & Result & Standard Deviation & COV & Result & Standard Deviation & COV \\
\hline Longitudinal Modulus $\mathrm{E}_{1}(\mathrm{GPa})$ & 37.8 & 4.2 & $11.1 \%$ & 101.1 & 13.5 & $13.4 \%$ \\
Longitudinal Strength $\sigma_{1}(\mathrm{MPa})$ & 518 & 53 & $10.2 \%$ & 618 & 79 & $12.8 \%$ \\
Transverse Modulus $\mathrm{E}_{2}(\mathrm{GPa})$ & 13.4 & 2.28 & $17.0 \%$ & 6.73 & 1.96 & $29.1 \%$ \\
Transverse Strength $\sigma_{2}(\mathrm{MPa})$ & 167 & 7.3 & $4.4 \%$ & 130 & 5.9 & $4.5 \%$ \\
\hline
\end{tabular}

\subsection{Mode I Interlaminar Fracture Toughness}

The Double Cantilever Beam (DCB) test results were processed according to ASTM D6671 using the Modified Beam Theory Method (MBT) given in Equation (2). The results are summarised in Table 3 where STD represents the standard deviation and COV the coefficient of variation. By coupling the video extensometer data to the test machine, it was possible to obtain the Force, Displacement and Crack Lengths in real time with a frequency of $0.1 \mathrm{~Hz}$. The DCB tests allowed between $40 \mathrm{~mm}$ and $60 \mathrm{~mm}$ of crack propagation so the propagation data were averaged over a large range of crack growth. The propagation $G_{I C}$ was measured as $1684 \pm 71 \mathrm{~J} / \mathrm{m}^{2}$ and $2067 \pm 285 \mathrm{~J} / \mathrm{m}^{2}$ respectively for the CFRP and GFRP samples. The critical initiation SERRs were measured as $1377 \pm 103 \mathrm{~J} / \mathrm{m}^{2}$ and $1643 \pm 112 \mathrm{~J} / \mathrm{m}^{2}$ for the GFRP samples using the NL method and $5 \%$ compliance method. Using these same methods, the critical initiation SERRs for the CFRP samples were measured as $851 \pm 74 \mathrm{~J} / \mathrm{m}^{2}$ and $1070 \mathrm{~J} / \mathrm{m}^{2}$. The $G_{I C}$ was therefore higher for the GFRP samples compared to the CFRP for both the initiation and propagation values. The NL, $5 \%$ compliance and propagation $G_{I C}$ were $62 \%, 54 \%$ and $22 \%$ higher respectively for the GFRP samples.

Table 3. Summary of DCB test results.

\begin{tabular}{|c|c|c|c|c|c|c|c|c|c|}
\hline & \multicolumn{6}{|c|}{ Initiation } & \multirow{2}{*}{\multicolumn{3}{|c|}{$\begin{array}{c}\text { Propagation } \\
\text { Mean R-Curve }\end{array}$}} \\
\hline & \multicolumn{3}{|c|}{ NL } & \multicolumn{3}{|c|}{$5 \%$ Compliance } & & & \\
\hline & $\begin{array}{l}\text { Mean } \\
\left(\mathrm{J} / \mathrm{m}^{2}\right)\end{array}$ & $\begin{array}{l}\text { STD } \\
\left(\mathrm{J} / \mathrm{m}^{2}\right)\end{array}$ & $\begin{array}{c}\mathrm{COV} \\
(\%)\end{array}$ & $\begin{array}{l}\text { Mean } \\
\left(\mathrm{J} / \mathrm{m}^{2}\right)\end{array}$ & $\begin{array}{c}\text { STD } \\
\left(\mathrm{J} / \mathrm{m}^{2}\right)\end{array}$ & $\begin{array}{c}\text { COV } \\
(\%)\end{array}$ & $\begin{array}{l}\text { Mean } \\
\left(\mathrm{J} / \mathrm{m}^{2}\right)\end{array}$ & $\begin{array}{c}\text { STD } \\
\left(\mathrm{J} / \mathrm{m}^{2}\right)\end{array}$ & $\begin{array}{c}\mathrm{COV} \\
(\%)\end{array}$ \\
\hline GFRP & 1377 & 103 & 7.5 & 1643 & 112 & 6.8 & 2048 & 268 & 13.1 \\
\hline CFRP & 851 & 74 & 8.7 & 1070 & 142 & 13.3 & 1684 & 71 & 4.2 \\
\hline
\end{tabular}

The force-displacement curves obtained at the loading blocks are shown in Figure 7. There was variability in the load-displacement curve throughout the test, highlighting the need to use as large a crack propagation as possible to obtain an accurate estimate of the propagation $G_{I C}$. The CFRP samples all had force-displacement plots which were increasing linearly until about $110 \mathrm{~N}$ followed by a non-linear increase to a peak around $135 \mathrm{~N}$ after which a sudden drop in the load of around $20 \mathrm{~N}$ occurred. During the remainder of the test, the force at the loading blocks went through successive periods of steady increase followed by rapid drops. This characteristic stick-slip behaviour is visible in the R-curves shown in Figure 8, in which the SERR was seen to fluctuate between linear increases followed by sudden reductions. Similar R-curves were noted for various resin materials such as PEEK [34], or epoxies [35]. The R-curves showed an increasing trend in the SERR 
in the first 20 to $30 \mathrm{~mm}$ of crack growth for the CFRP samples followed by area period over which the SERR seemed to have stabilised, despite the peaks and troughs in the SERR data. The GFRP samples showed more variability in the force-displacement curves with the peak load varying from $90 \mathrm{~N}$ to $105 \mathrm{~N}$. The subsequent reduction in the load was much smoother than the CFRP samples. However, in some of the samples, large increases in the load were visible in the crack propagation region. In the example R-curve shown in Figure 7 for the GFRP samples, this increase in load was visible in the form of a rapid, near vertical increase in the SERR. The trend in the GFRP R-curves was less clear than for the CFRP samples. There was an initial increase in the SERR in the first 5 to $10 \mathrm{~mm}$ of crack growth. However, following this initial crack extension, the R-curves showed varying trends with some showing a plateau, while others had sudden increases followed by reductions in the measured SERR.
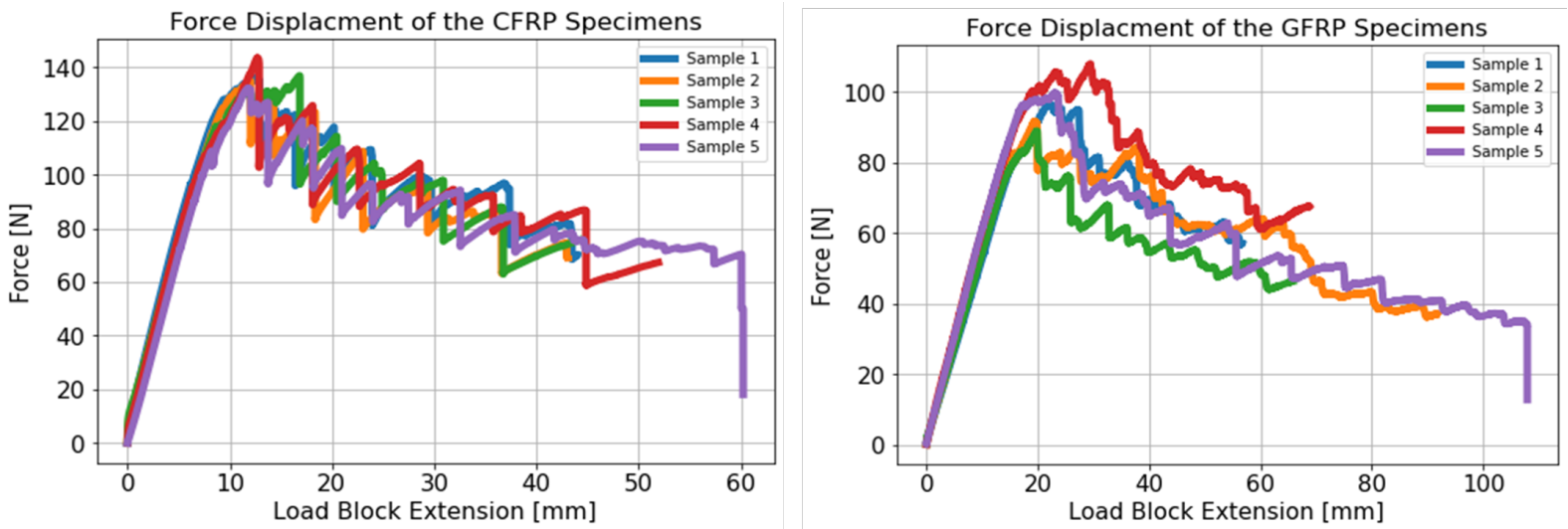

Figure 7. Load-Displacement curves for the DCB samples.
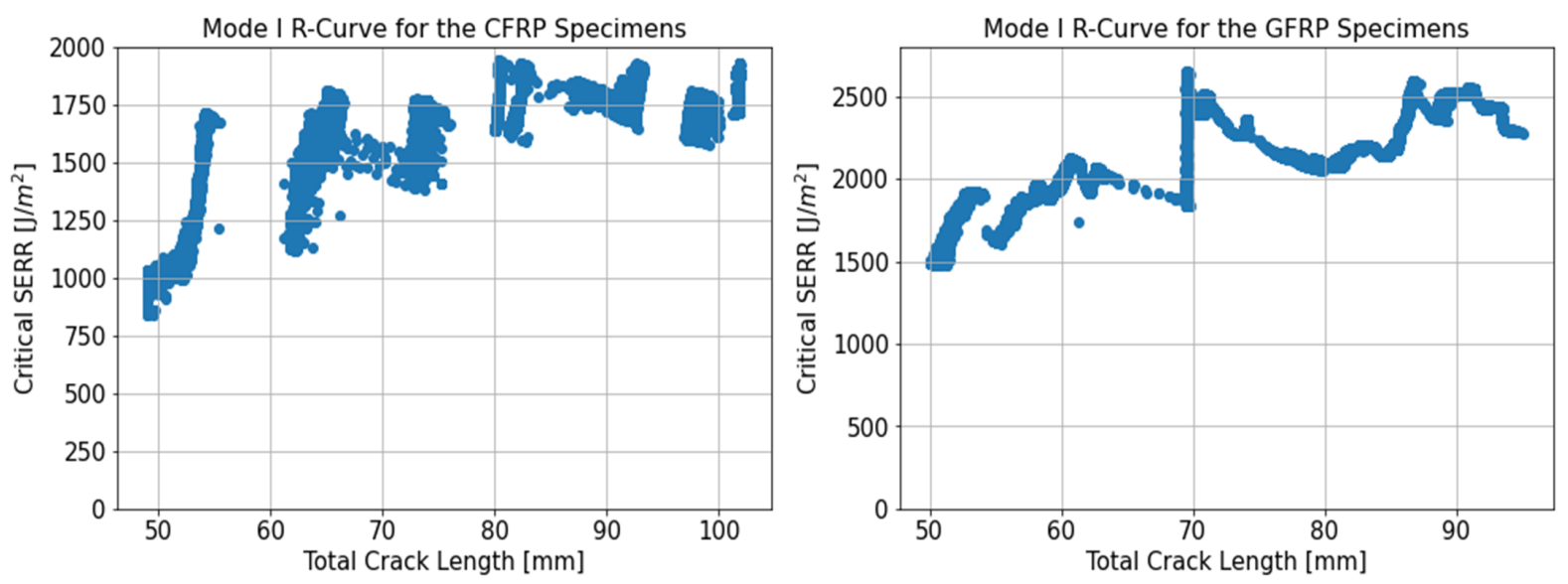

Figure 8. Representative Mode I R-curves for CFRP and GFRP specimens.

\subsection{Mixed-Mode Interlaminar Fracture Toughness}

Prior to the start of the test, the appropriate lever arm lengths had to be selected to ensure the experiment was performed at the desired mode ratio. Using Equations (3)-(7), the arm lengths were determined and are summarised in Table 4. The MMB test standard [30] recommended using the value of $G_{12}$ instead of $G_{13}$ if the out-of-plane shear modulus was not available, provided the studied materials were unidirectional. For the GFRP samples, values of $E_{1}=39.4 \mathrm{GPa}, E_{2}=13.7 \mathrm{GPa}$ and $G_{12}=3.91 \mathrm{GPa}$ were used for Equations (6) and (7) while values of $E_{1}=123.0 \mathrm{GPa}, E_{w}=8.47 \mathrm{GPa}$ and $\mathrm{G}_{12}=4.30 \mathrm{GPa}$ were selected for the CFRP samples. These values were obtained during tensile testing performed prior to the MMB tests and highlight the importance of knowing the in-plane material elastic properties to obtain an accurate estimate of the mode ratio. Figure 9 shows 
an example of the Force-Displacement curves obtained at the three mode ratios for the CFRP and GFRP samples. The load at delamination onset and propagation increased with mode ratio while the displacement decreased. Using Equations (8) and (9), the mode I, mode II and total SERR were measured at the point of Non-linearity (NL), the 5\% compliance point and at every subsequent point throughout the test until the crack length reached $60 \mathrm{~mm}$. Above this value, the crack propagated beyond the point of contact between the roller at the mid-span of the sample so it was no longer a delamination test, with the upper arm of the sample being loaded in bending. The MMB test results are summarised in Tables 5 and 6.
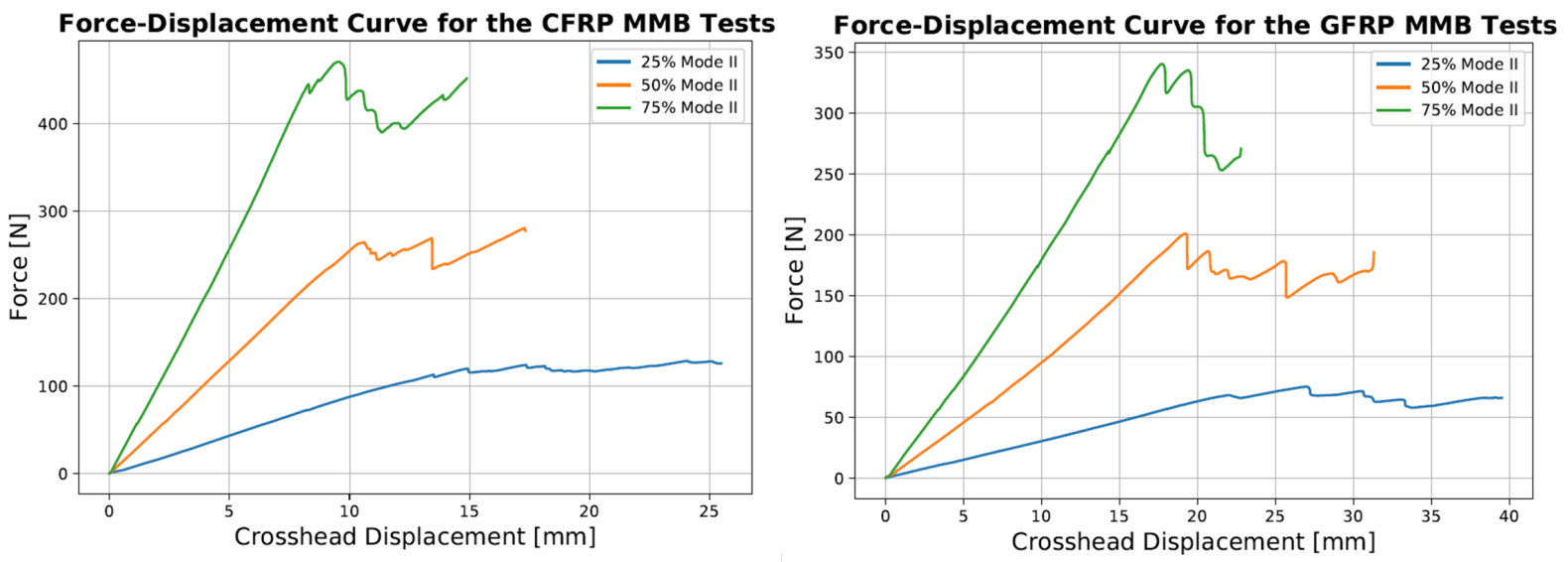

Figure 9. Representative Force-Displacement Curves for the GFRP and CFRP MMB tests at the different mode ratios.

Table 4. Lever arm lengths for the MMB test setup.

\begin{tabular}{lccc}
\hline & $\mathbf{2 5}$ \% Mode II & $\mathbf{5 0 \%}$ Mode II & $\mathbf{7 5 \%}$ Mode II \\
\hline Lever Length CFRP $(\mathrm{mm})$ & 94.2 & 50.8 & 35.3 \\
Lever Length GFRP $(\mathrm{mm})$ & 96.3 & 51.4 & 35.5 \\
\hline
\end{tabular}

Table 5. Summary of CFRP MMB test results.

\begin{tabular}{|c|c|c|c|c|c|c|c|c|c|}
\hline & \multicolumn{6}{|c|}{ Initiation } & \multirow{2}{*}{\multicolumn{3}{|c|}{$\begin{array}{c}\text { Propagation } \\
\text { Mean R-Curve }\end{array}$}} \\
\hline & \multicolumn{3}{|c|}{ NL } & \multicolumn{3}{|c|}{ 5\% Compliance } & & & \\
\hline & $\begin{array}{l}\text { Mean } \\
\left(\mathrm{J} / \mathrm{m}^{2}\right)\end{array}$ & $\begin{array}{l}\text { STD } \\
\left(\mathrm{J} / \mathrm{m}^{2}\right)\end{array}$ & $\begin{array}{c}\text { COV } \\
(\%)\end{array}$ & $\begin{array}{l}\text { Mean } \\
\left(\mathrm{J} / \mathrm{m}^{2}\right)\end{array}$ & $\begin{array}{c}\text { STD } \\
\left(\mathrm{J} / \mathrm{m}^{2}\right)\end{array}$ & $\begin{array}{c}\text { COV } \\
(\%)\end{array}$ & $\begin{array}{l}\text { Mean } \\
\left(\mathrm{J} / \mathrm{m}^{2}\right)\end{array}$ & $\begin{array}{c}\text { STD } \\
\left(\mathrm{J} / \mathrm{m}^{2}\right)\end{array}$ & $\begin{array}{c}\text { COV } \\
(\%)\end{array}$ \\
\hline $25 \%$ Mode II & 1024 & 186 & 18.2 & 1529 & 192 & 12.5 & 2164 & 190 & 8.8 \\
\hline $50 \%$ Mode II & 1443 & 198 & 13.7 & 1976 & 150 & 7.6 & 2418 & 140 & 5.8 \\
\hline 75\% Mode II & 2059 & 573 & 27.8 & 2562 & 187 & 7.3 & 3241 & 367 & 11.3 \\
\hline
\end{tabular}

Table 6. Summary of GFRP MMB test results.

\begin{tabular}{|c|c|c|c|c|c|c|c|c|c|}
\hline & \multicolumn{6}{|c|}{ Initiation } & \multirow{2}{*}{\multicolumn{3}{|c|}{$\begin{array}{c}\text { Propagation } \\
\text { Mean R-Curve }\end{array}$}} \\
\hline & \multicolumn{3}{|c|}{ NL } & \multicolumn{3}{|c|}{$5 \%$ Compliance } & & & \\
\hline & $\begin{array}{l}\text { Mean } \\
\left(\mathrm{J} / \mathrm{m}^{2}\right)\end{array}$ & $\begin{array}{l}\text { STD } \\
\left(\mathrm{J} / \mathrm{m}^{2}\right)\end{array}$ & $\begin{array}{c}\text { COV } \\
(\%)\end{array}$ & $\begin{array}{l}\text { Mean } \\
\left(\mathrm{J} / \mathrm{m}^{2}\right)\end{array}$ & $\begin{array}{c}\text { STD } \\
\left(\mathrm{J} / \mathrm{m}^{2}\right)\end{array}$ & $\begin{array}{c}\text { COV } \\
(\%)\end{array}$ & $\begin{array}{l}\text { Mean } \\
\left(\mathrm{J} / \mathrm{m}^{2}\right)\end{array}$ & $\begin{array}{c}\text { STD } \\
\left(\mathrm{J} / \mathrm{m}^{2}\right)\end{array}$ & $\begin{array}{c}\text { COV } \\
(\%)\end{array}$ \\
\hline $25 \%$ Mode II & 1499 & 125 & 8.4 & 1619 & 133 & 8.2 & 1792 & 186 & 10.4 \\
\hline $50 \%$ Mode II & 2132 & 143 & 6.7 & 2728 & 390 & 14.3 & 3374 & 427 & 12.7 \\
\hline 75\% Mode II & 3118 & 215 & 6.9 & 4555 & 319 & 7.0 & 5151 & 404 & 7.8 \\
\hline
\end{tabular}

Example R-curves from the point of 5\% compliance until the crack length reach $60 \mathrm{~mm}$ are shown in Figure 10. For this range of crack extension, the R-curves for the three different mode ratios for CFRP displayed an increasing trend from the $5 \%$ compliance point until the 
end of the test. The R-Curves for the GFRP samples were flatter, despite some fluctuations and showed no clear trends despite some notable differences between the samples. The shorter distance of crack propagation of between 10 and $15 \mathrm{~mm}$, depending on the samples, results in fewer values over which to average the SERR. Therefore, care needs to be taken comparing the mean R-curve results of the DCB test to the mixed-mode test. This is why comparison between mode I and mixed-mode SERR data will be carried out using the initiation $G_{I C}$ as well as a mean R-curve value from the DCB tests for the first $12.5 \mathrm{~mm}$ of crack growth.
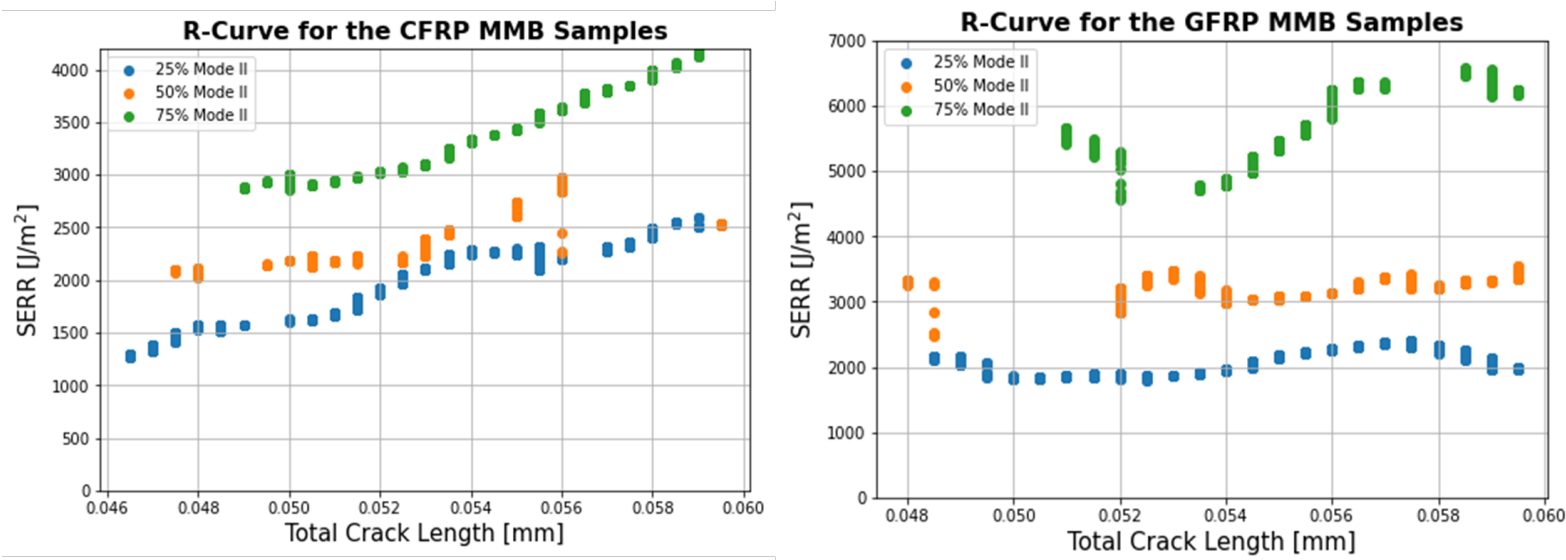

Figure 10. Representative R-Curves for the CFRP and GFRP samples at the 3 Mode Ratios.

\section{Discussion}

\subsection{Performance of Powder Epoxy Compared to Standard Epoxy in Tension and Compression}

The performance of the powder epoxy carbon fibre samples can be evaluated by using a material datasheet from Zoltek ${ }^{\mathrm{TM}}$ [36] which lists the longitudinal mechanical properties of UD Zoltek PX35 unidirectional fabrics manufactured using standard epoxy resin with an FVF of $55 \%$. This was used to compare the properties obtained using standard epoxy resin. As the datasheet did not specify the exact composition of the resin, fabric, and manufacturing method, it was difficult to perform a rigorous comparison between the two epoxy systems. However, the obtained longitudinal strength and stiffness of $1492 \mathrm{MPa}$ and 123 GPa respectively measured here were higher than the $1400 \mathrm{MPa}$ and $119 \mathrm{GPa}$ listed by the manufacturer, suggesting that despite slight distortions in the fibre alignment within the samples, a good manufacturing quality was achieved for the samples, despite a slightly lower FVF (51.1\% vs. 55\% in the data sheet). Although it is difficult to find mechanical properties in literature for glass fibre reinforced epoxies with the same fibre architecture, the powder epoxy reinforced glass fibre composites performed well compared to conventional epoxy systems $[37,38]$.

The reductions in longitudinal and transverse stiffness observed in compression testing of the CFRP samples of $18 \%$ and $20 \%$ respectively were more than expected [36] and are perhaps linked to the slight distortion of the fibre orientation during manufacturing. During a tensile test, these fibres are straightened in the initial part of the test, leading to a higher stiffness while this phenomenon does not occur in a compression test. A 59\% reduction in the longitudinal strength was measured in compression compared to tension as compared to the $30 \%$ reduction reported in the Zoltek datasheet with a compressive strength of $980 \mathrm{MPa}$ [36]. Another study performed on pultruded Zoltek PX35 with epoxy resin showed a reduction in the compressive strength of $43 \%$ to a value of $897 \mathrm{MPa}$ [39]. On the other hand, the glass fibre samples showed only a minor reduction in the longitudinal stiffness in compression, suggests that the measured lower stiffness of the CFRP in compression is not related to poor performance of the powder epoxy. The measured compressive strength was $48 \%$ lower than the tensile strength. In a study on the influence of fibre volume fraction (FVF) on the tensile and compressive properties of glass/epoxy 
composites [40], the compressive strength at 50\% FVF was reported as $600 \mathrm{MPa}$ compared to $900 \mathrm{MPa}$ for the tensile strength, representing a 33\% difference. In another study [41], representative mechanical properties for E-glass epoxy with $60 \%$ FVF show a tensile and compressive longitudinal strengths of $1020 \mathrm{MPa}$ and $600 \mathrm{MPa}$ for a reduction of $39 \%$. The glass fibre/powder epoxy composite had a compressive strength that was $14 \%$ lower than these two materials.

Therefore, the tensile and compression test results for both the glass and carbon reinforced powder epoxy composites show that the in-plane mechanical performance of these composites is comparable to and, in some cases, better than that of conventional epoxy composites despite a slightly lower compressive longitudinal strength .

\subsection{Differences in Measured Toughness between GFRP and CFRP Specimen}

The aim of this work is to characterise the mixed-mode fracture toughness properties of powder epoxy composites reinforced with carbon and glass fibres. It is not possible to perform a direct rigorous comparison between the performance of the CFRP and GFRP samples, however, as mentioned above, because of differences in the reinforcing fabric architecture. Nevertheless, the differences in behaviour can be discussed as well as possible explanations for these observed differences.

The carbon and glass fibre fabrics used in this study have different configurations, even though both are classified as unidirectional (UD). In most studies on the interlaminar fracture toughness properties found in literature, the precise composition of the UD fabrics is not specified, despite most having off-axis fibres and stitching to keep the fibres in the correct alignment during manufacturing. The UD carbon fabric tested here has $\pm 60^{\circ}$ degree fibres and stitching representing $2.6 \%$ and $1.0 \%$ of the areal weight respectively while the UD glass fabric has $9.1 \%$ content of $90^{\circ}$ fibres, as well as $2.9 \%$ stitching. The offaxis fibres in the carbon fabric clearly play a role, most visibly in the DCB test as evidenced in Figure 11. The presence of these fibres may explain the observed stick-slip behaviour on the force-displacement curves and the corresponding peaks and troughs of the R-curves. As the crack propagates, the $\pm 60^{\circ}$ fibres are pulled out and bridge the crack, therefore artificially delaying propagation and increasing the apparent SERR. This is followed by breakage of these fibres, leading to sudden drops in both the measured force. In the GFRP specimens, as the off-axis fibres were at a $90^{\circ}$ angle, the bridging mechanism is different. Fibre bridging is no longer visible from the side view of the sample as captured by the video extensometer, but as shown in Figure 12, they still impede crack growth and, in some cases, result in a non-uniform crack front. Figure 12 also shows that the presence of the $90^{\circ}$ fibres sometimes forces damage to spread from the interlaminar region into the adjacent ply, which could explain the sudden increases in the measured SERR observed in the R-curve shown in Figure 8 where crack propagation was momentarily arrested. This may also explain the higher variability observed in the GFRP samples with a COV of $13.1 \%$ compared to $4.2 \%$ for CFRP specimens, as the fibre bridging is less uniform during crack propagation.

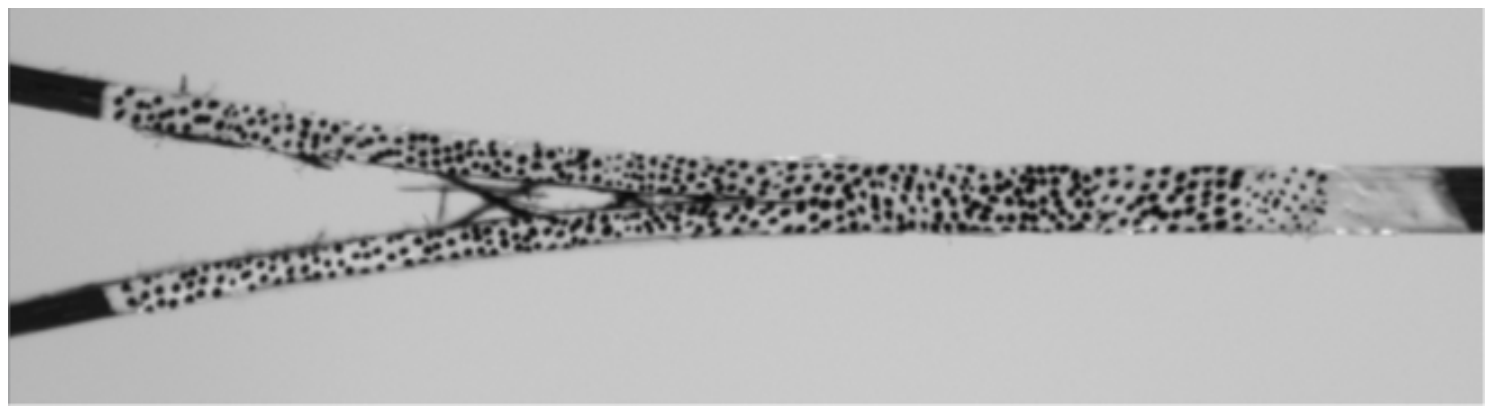

Figure 11. CFRP DCB sample during testing with off-axis fibre bridging. 


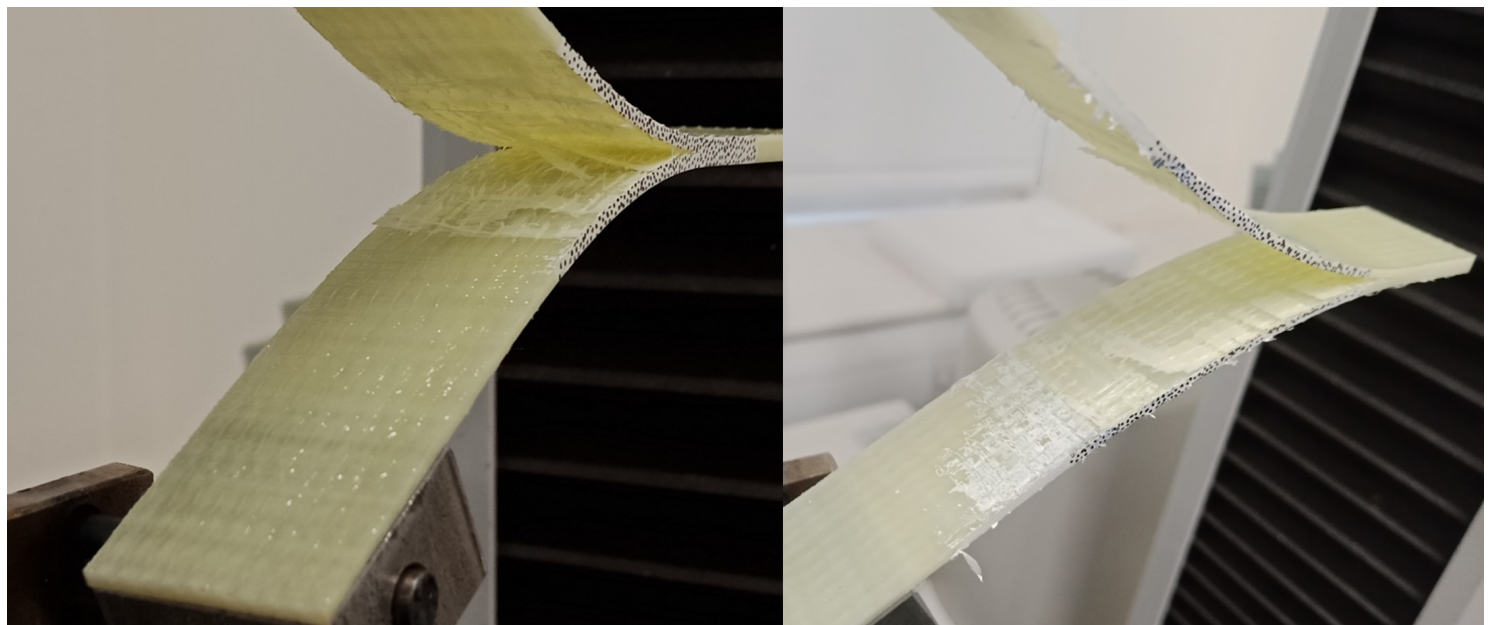

Figure 12. GFRP sample during testing with $90^{\circ}$ fibre bridging.

The glass fibre samples showed higher initiation and propagation values for the mode I and the three different mode ratios studied in this work, except for the mean R-curve value for the $25 \%$ mode II test. A possible explanation may be the high standard deviation measured in these samples, or perhaps that the R-curve takes longer to increase to a stable value in the GFRP samples in a test where only the first $13 \mathrm{~mm}$ of crack growth were observed. The largest absolute difference in the measured critical SERR, however, was for the $75 \%$ mode II case. This is probably explained by the presence of the $90^{\circ}$ fibres in the GFRP samples impeding crack propagation in mode II dominated failure more effectively than the $\pm 60^{\circ}$ fibres found in the CFRP samples. The difference in orientation of the off-axis fibres as well as the higher percentage of these fibres in the UD GFRP fabric is believed to be the main factor in the higher measured SERR both at initiation and propagation. Other factors, however, such as the difference in stiffness between carbon and glass fibres, cannot be excluded. In this work, CFRP and GFRP samples were studied primarily with the aim of being able to compare their relative performances under mixed-mode loading with regards to other GFRP and CFRP composites results found in the literature rather than with each other.

\subsection{Fractography of $M M B$ Samples}

After testing, the MMB samples were coated in a thin layer of gold and observed under a TM4000Plus Scanning Electron Microscope (SEM) manufactured by Hitachi (Tokyo, Japan). The most notable difference in the fracture surfaces of the glass and carbon powder epoxy composites is the presence of a greater number of pulled-out fibres in the glass specimens. This is caused by the higher number of off-axis fibres in the glass fabric. However, most of the failure phenomena observed were similar for both glass and carbon samples. Therefore, SEM pictures of the $25 \%$ mode ratio for the GFRP samples (Figure 13), and the CFRP 75\% mode ratio (Figure 14) were used to illustrate the main fracture mechanisms which occurred during delamination.

Hackle patterns, characteristic of mode I delamination are found on both the GFRP and CFRP fracture surfaces as shown in Figure 13. These features were also observed in literature for mode I dominated delamination tests [42,43]. Hackle patterns, characteristic of mode II delamination $[32,43]$ are also visible in the $25 \%$ mode ratio specimens but are far more present in the $75 \%$ mode ratio samples as shown in Figure 14. Fibre pull-out and breakage, which were visible in Figures 11 and 12 are present on the fracture surfaces of both the $25 \%$ and $75 \%$ mode ratio samples. 


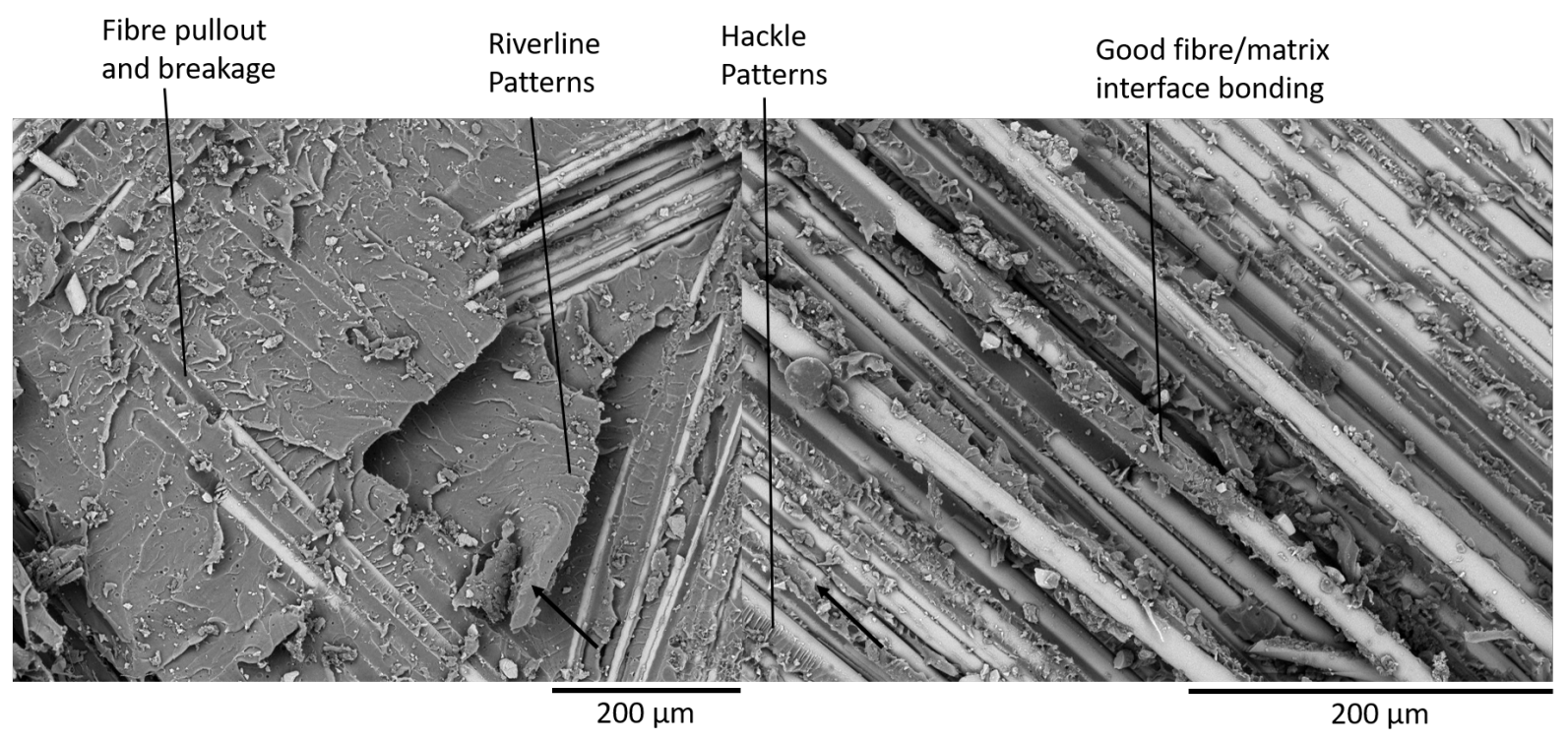

Figure 13. 25\% Mode Ratio Fracture Surface of GFRP Specimen (Crack Direction shown by the Arrow).

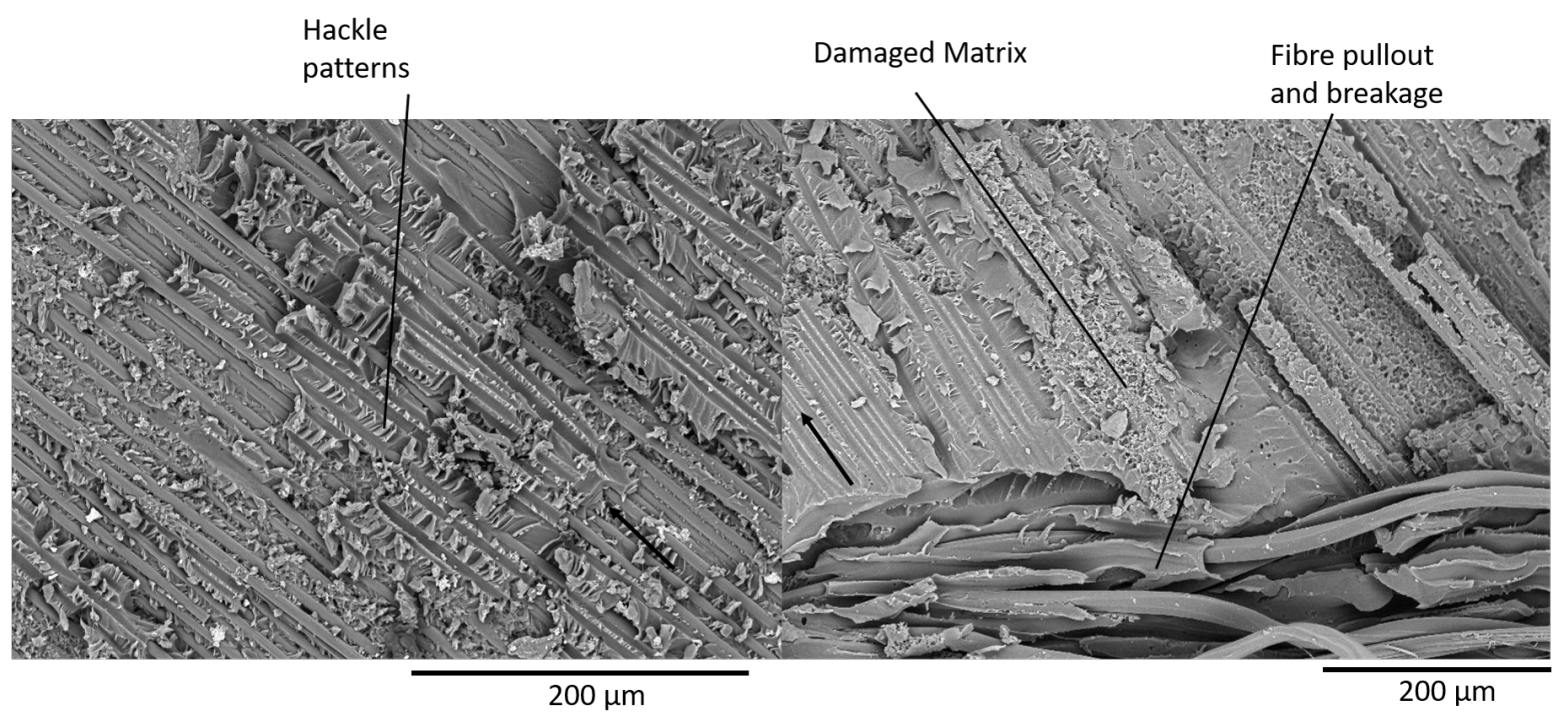

Figure 14. 75\% Mode Ratio Fracture Surface of CFRP specimen (crack direction shown by the arrow).

Another interesting feature observed during SEM analysis is the presence of a highly damaged matrix. This was slightly more prevalent in the $75 \%$ mode ratio samples but it was also found in the samples tested at $25 \%$ mode ratio. This feature, present in both the GFRP and CFRP samples, has not been reported in the literature. It may perhaps explain the very high toughness measured in powder epoxy composites. Additionally, all samples displayed a fracture surface with a high roughness, suggesting that the crack progression was not smooth along the length of the sample.

\subsection{Comparison of Powder Epoxy SERR with Other Resin Systems}

A list of mixed-mode critical initiation SERR values found in a literature survey is summarised in Table 7. As the different studies were performed at various mode ratios, the relevant mode ratios for each material are specified. In most cases, the reported SERR corresponds to the initiation SERR, although it is not always clear if that corresponds to the NL point or the $5 \%$ compliance point. Table 7 does not aim to present an exhaustive list of results, but rather to show representative results obtained for the mixed-mode toughness of both standard and toughened epoxy composites. As mentioned in Section 4.1, in most 
cases, the exact fabric fibre architecture of the studied materials is unknown and therefore direct comparisons are not possible. It is clear from the presented results, however, that powder epoxy composites perform very well in terms of SERR, even when compared to epoxies toughened with rubber or even multi-walled carbon nanotubes. Indeed, the mode I SERR measured at the NL point was more than double for the CFRP and GFRP powder epoxy composites compared to the reported values in Table 7. This is also true for the mixed-mode tests, with the CFRP and GFRP powder epoxy showing critical Gc values of up to three times those reported in the literature even for toughened epoxy composites. This study therefore shows that powder epoxy composites have toughness that is higher than most toughened epoxies available on the market. To the knowledge of the authors, no published results showed an epoxy composite with higher toughness than these powder epoxy composites. It is therefore a very good material choice in structures exposed to a high risk of delamination.

Table 7. MMB test results for GF and CF epoxy composites.

\begin{tabular}{|c|c|c|c|c|c|c|}
\hline & Material & & & & & \\
\hline \multirow{10}{*}{ GFRP } & \multirow{2}{*}{ UD GF/Epoxy with 5\% $90^{\circ}$ Fibres [32] } & Mode Ratio & $0 \%$ & $28 \%$ & $53 \%$ & $72 \%$ \\
\hline & & Initiation SERR $\left(\mathrm{J} / \mathrm{m}^{2}\right)$ & 118 & 340 & 580 & 1034 \\
\hline & \multirow{2}{*}{ UD GF/Epoxy hand layup [44] } & Mode Ratio & $0 \%$ & $23 \%$ & $47 \%$ & $75 \%$ \\
\hline & & Initiation SERR $\left(\mathrm{J} / \mathrm{m}^{2}\right)$ & 300 & 480 & 680 & 950 \\
\hline & \multirow{2}{*}{ UD GF/rubber toughened epoxy [45] } & Mode Ratio & $0 \%$ & $27 \%$ & $44 \%$ & \\
\hline & & Initiation SERR $\left(\mathrm{J} / \mathrm{m}^{2}\right)$ & 440 & 473 & 743 & \\
\hline & \multirow{2}{*}{ UD GF/MWCNT toughened epoxy [46] } & Mode Ratio & $0 \%$ & $33 \%$ & $50 \%$ & $67 \%$ \\
\hline & & Initiation SERR $\left(\mathrm{J} / \mathrm{m}^{2}\right)$ & 235 & 666 & 719 & 1150 \\
\hline & \multirow{2}{*}{$\begin{array}{l}\text { UD GF / Powder Epoxy with } 9.1 \% 90^{\circ} \text { Fibres } \\
\text { and } 2.9 \% \text { Stitching }\end{array}$} & Mode Ratio & $0 \%$ & $25 \%$ & $50 \%$ & $75 \%$ \\
\hline & & Initiation SERR $\left(\mathrm{J} / \mathrm{m}^{2}\right)$ & 1377 & 1499 & 2132 & 3118 \\
\hline \multirow{10}{*}{ CFRP } & \multirow{2}{*}{ UD CF IM7/977-2 toughened epoxy [47] } & Mode Ratio & $0 \%$ & $25 \%$ & $50 \%$ & $75 \%$ \\
\hline & & Initiation SERR $\left(\mathrm{J} / \mathrm{m}^{2}\right)$ & 310 & 420 & 840 & 1280 \\
\hline & \multirow{2}{*}{ UD T700/SR8100 with $2.2 \% 90^{\circ}$ Fibres [48] } & Mode Ratio & $0 \%$ & $25 \%$ & $50 \%$ & $75 \%$ \\
\hline & & Initiation SERR $\left(\mathrm{J} / \mathrm{m}^{2}\right)$ & 281 & 348 & 544 & 581 \\
\hline & \multirow{2}{*}{ UD T300/toughened epoxy prepreg (HS160) [49] } & Mode Ratio & $0 \%$ & $28 \%$ & $55 \%$ & $85 \%$ \\
\hline & & Initiation SERR $\left(\mathrm{J} / \mathrm{m}^{2}\right)$ & 250 & 350 & 510 & 710 \\
\hline & \multirow{2}{*}{ YTEC G40-800/5276-1 UD prepreg [50] } & Mode Ratio & $0 \%$ & $25 \%$ & $50 \%$ & $75 \%$ \\
\hline & & Initiation SERR $\left(\mathrm{J} / \mathrm{m}^{2}\right)$ & 320 & 404 & 721 & 1143 \\
\hline & \multirow{2}{*}{$\begin{array}{c}\text { UD CF / Powder Epoxy with } 2.6 \% \pm 60^{\circ} \text { Fibres } \\
\text { and } 1.0 \% \text { Stitching }\end{array}$} & Mode Ratio & $0 \%$ & $25 \%$ & $50 \%$ & $75 \%$ \\
\hline & & Initiation $\operatorname{SERR}\left(\mathrm{J} / \mathrm{m}^{2}\right)$ & 851 & 1024 & 1443 & 2059 \\
\hline
\end{tabular}

\subsection{Mixed Mode Bending Criteria}

The Power Law and B-K curve fitting of the critical SERR vs mode ratio are shown in Figure 15 for the $5 \%$ compliance initiation point and in Figure 16 for the propagation SERR defined as the mean R-curve from the point of $5 \%$ compliance until the crack has propagated to a total length of $60 \mathrm{~mm}$. The exponent $n$ in the B-K curve fit was found to be equal to 1.49 and 1.43 in the CFRP samples at the $5 \%$ compliance and propagation SERR exponent in the Power Law, $\alpha$, was found to be equal to 1.19 and 0.97 . For the GFRP specimens, the BK exponent was equal to 2.47 and 2.10 for the $5 \%$ compliance and propagation SERR values respectively while the Power Law exponent had a value of 1.39 and 1.54. 
Using either of these fitting methods, it is possible to estimate the critical SERR value for any mode ratio. This may therefore serve as the input to a Finite Element delamination analysis, and these two curve fitting methods were selected because they are incorporated in some of the widely used commercial FE packages such as Abaqus ${ }^{\mathrm{TM}}$ and Ansys ${ }^{\mathrm{TM}}$. It is difficult to comment on the relative performance of the B-K and Power Law curve fitting methods as there is data presented for only four different mode ratios. Additionally, in the absence of $100 \%$ mode II data, the mode II SERR was introduced as a bounded variable during curve fitting. In any case, the existence of pure mode II test values is open to discussion, due to the influence of friction [51] so it may be more reliable to base estimations for $G_{I I C}$ on mixed mode extrapolations. Generally, mode II SERR was estimated to be higher using the Power Law compared to the B-K fit. However, apart from the mode ratios close to 1 , the estimated SERR were very similar with only minor differences between the two approaches. The variability in the SERR experimental data is much higher than the differences obtained between the two curve fitting methods, suggesting that both would be acceptable as an input to a mixed mode delamination analysis.
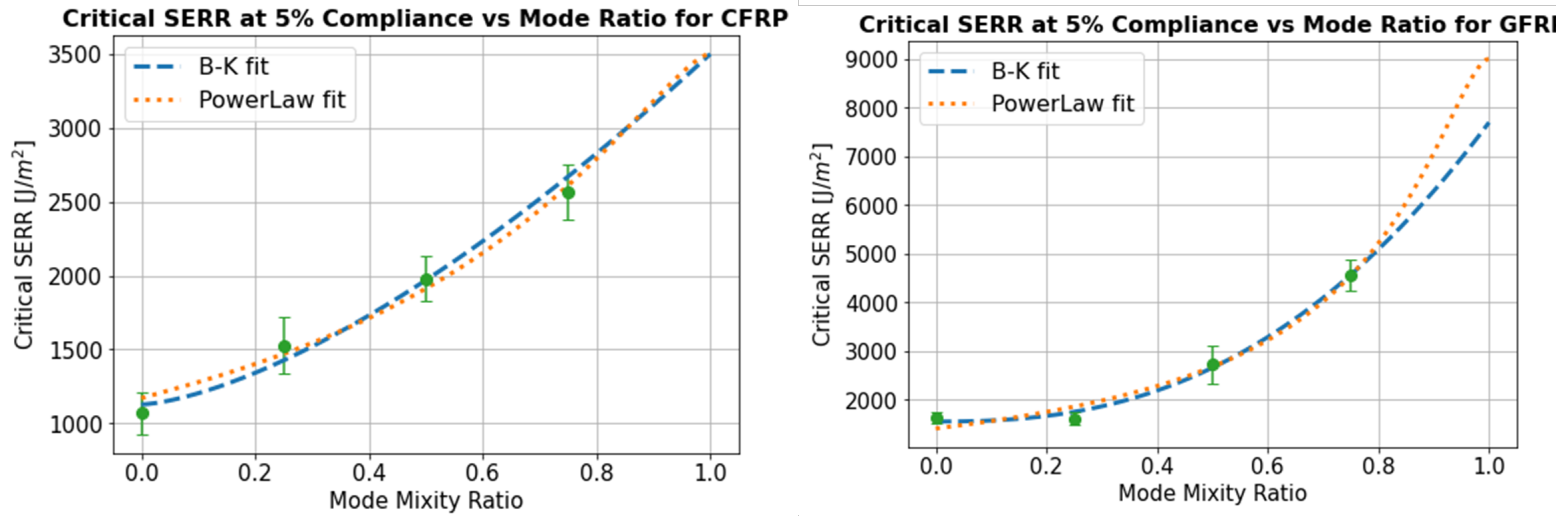

Figure 15. Initiation: SERR at 5\% compliance vs. mode ratio for the CFRP and GFRP samples.
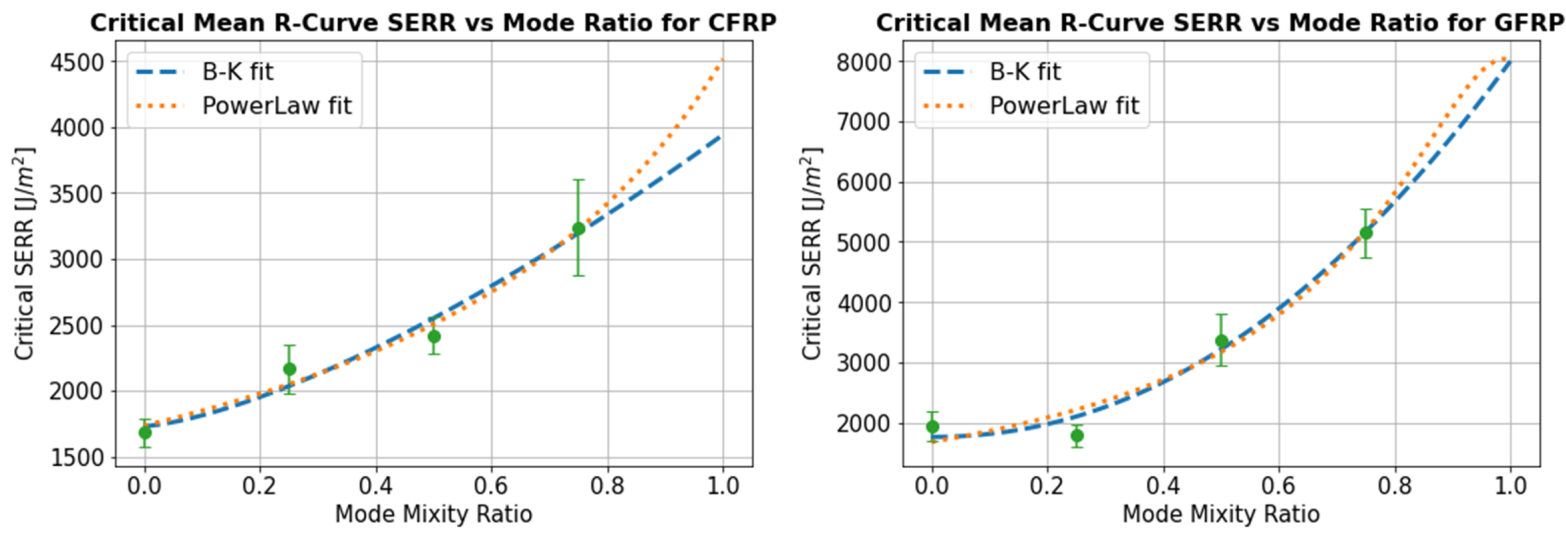

Figure 16. Propagation: mean R-curve SERR vs. mode ratio for the CFRP and GFRP samples.

\section{Conclusions}

Powder epoxy has been shown in previous work to have very good properties for the manufacturing of large composite structures [14,15], with low minimal viscosity [16-18], low exotherm [16], no VOCs released, the capacity for long term room temperature storage and its suitability for out-of-autoclave manufacturing. As part of this study, unidirectional stitched carbon fibre and glass fibre composites reinforced with powder epoxy were manufactured. The quality of the specimens was found to be adequate for a study on the mechanical properties, with no observable voids, consistent thicknesses, and low variations of the fibre volume fractions between the samples. 
The tensile and compressive in-plane mechanical properties of the powder epoxy composites were determined for these samples and are shown to be comparable to those of commonly used epoxy resin systems. The interlaminar fracture toughness was studied in pure mode I by performing Double Cantilever Beam tests and at $25 \%$ mode II, $50 \%$ mode II and $75 \%$ mode II by performing Mixed Mode Bending testing. The SERRs at both crack initiation and propagation were shown to be significantly higher than both conventional and toughened epoxy composites for which published data is available, with initiation $G_{C}$ values ranging between $1377 \mathrm{~J} / \mathrm{m}^{2}$ and $3118 \mathrm{~J} / \mathrm{m}^{2}$ for the GFRP powder epoxy composites and from $851 \mathrm{~J} / \mathrm{m}^{2}$ to $2059 \mathrm{~J} / \mathrm{m}^{2}$ for CFRP. An SEM fractography revealed the presence of riverline and hackle patterns typical of mode I and mode II delamination, but also the presence of a highly damaged resin, giving a possible explanation for the high measured toughness. The Benzeggagh-Kenane and Power Law equations were used for curve fitting of the mixed-mode SERR data, allowing an estimation of the critical SERR envelope for any mode ratio. Both methods were found to give similar results.

The high measured toughness of the powder epoxy composites does not come with the disadvantage of increased resin cost, which is normally associated with the toughened epoxies found in the literature. These toughened epoxies can also require an additional processing step, which further adds to cost. Considering the processing advantages of the powder epoxy system, combined with a very high toughness, this study suggests that the material is a very good candidate resin system for structures for which delamination may be a concern.

Author Contributions: Sample Manufacturing and Testing, C.F. and C.R.; conceptualization, C.F., C.R., P.A., P.D., C.M.OB.; methodology, C.F., C.R., P.D.; software, C.F.; validation, C.F.; formal analysis, C.F.; investigation, C.F.; resources, C.F. and P.D.; data curation, C.F.; writing-orginal draft preparation, C.F.; writing—review and editing, C.R., P.A., P.D., C.M.ÓB.; visualization, C.F.; supervision, P.A., P.D. and C.M.ÓB.; project administration, C.F. and C.M.ÓB.; funding acquisition, P.D. and C.M.ÓB. All authors have read and agreed to the published version of the manuscript.

Funding: Materials used in this research were funded by the PowderBlade H2020 (grant No 730747) European Project. Access to the IFREMER test facilities was funded by the EU Horizon 2020 MARINET2 (grant No 731084) programme.

Institutional Review Board Statement: Not applicable.

Informed Consent Statement: Not applicable.

Data Availability Statement: Data sharing is not applicable for this article.

Acknowledgments: The authors are grateful to the EU Horizon 2020 MARINET2 (grant No 731084) programme for providing the opportunity to perform part of the tests at the IFREMER facility in Brest. They would also like to thank the team at the IFREMER, including Antoine Le Guen-Geffroy for their assistance during the test programme. The authors would also like to thank PowderBlade H2020 (grant No 730747) European Project for providing funding for the fabrics used in this research project. The authors are also grateful to FreiLacke and Swiss CMT AG for supplying the powder epoxy resin.

Conflicts of Interest: The authors declare no conflict of interest.

\section{References}

1. Harper, P.W.; Hallett, S.R. A fatigue degradation law for cohesive interface elements-Development and application to composite materials. Int. J. Fatigue 2010, 32, 1774-1787. [CrossRef]

2. Wisnom, M.R. The role of delamination in failure of fibre-reinforced composites. Philos. Trans. R. Soc. A Math. Phys. Eng. Sci. 2012, 370, 1850-1870. [CrossRef]

3. Tabiei, A.; Zhang, W. Composite Laminate Delamination Simulation and Experiment: A Review of Recent Development. Appl. Mech. Rev. 2018, 70, 030801. [CrossRef]

4. Pascoe, J.; Alderliesten, R.; Benedictus, R. Methods for the prediction of fatigue delamination growth in composites and adhesive bonds-A critical review. Eng. Fract. Mech. 2013, 112-113, 72-96. [CrossRef]

5. Bak, B.L.V.; Sarrado, C.; Turon, A.; Costa, J. Delamination Under Fatigue Loads in Composite Laminates: A Review on the Observed Phenomenology and Computational Methods. Appl. Mech. Rev. 2014, 66. [CrossRef] 
6. Davies, G.A.O.; Olsson, R. Impact on composite structures. Aeronaut. J. (1968) 2004, 108, 541-563. [CrossRef]

7. Zhang, H.; Bilotti, E.; Peijs, T. The use of carbon nanotubes for damage sensing and structural health monitoring in laminated composites: A review. Nanocomposites 2015, 1, 167-184. [CrossRef]

8. Murray, R.; Snowberg, D.R.; Berry, D.S.; Beach, R.; Rooney, S.A.; Swan, D. Manufacturing a 9-Meter Thermoplastic Composite Wind Turbine Blade: Preprint. In Proceedings of the American Society for Composites 32nd Technical Conference, West Lafayette, IN, USA, 23-25 October 2017. [CrossRef]

9. Obande, W.; Ó Brádaigh, C.M.; Ray, D. Continuous fibre-reinforced thermoplastic acrylic-matrix composites prepared by liquid resin infusion-A review. Compos. Part B Eng. 2021, 108771. [CrossRef]

10. Price, R.V. Production of Impregnated Rovings. U.S. Patent 3742106, 26 June 1973.

11. Edie, D.; Lickfield, G.; Allen, L.; Mccollum, J. Thermoplastic Coating of Carbon Fibers: Annual Report, 1988-1989; Sponsored by the National Aeronautics and Space Administration, Langley Research Center; Center for Advanced Engineering Fibers, Clemson University: Clemson, SC, USA, 1989; p. 1 v.

12. Baucom, R.M.; Marchello, J.M. Powder towpreg process development. In Proceedings of the NASA Advanced Composites Technology Conference, Seattle, WA, USA, 29 October-1 November 1990; pp. 443-454.

13. Bayha, T.D.; Osborne, P.P.; Thrasher, T.P.; Hartness, J.T.; Johnston, N.J.; Marchello, J.M.; Hugh, M.K. Processing, Properties and Applications of Composites Using Powder-Coated Epoxy Towpreg Technology. In Proceedings of the 4th NASA/DoD Advanced Composites Technology Conference, Salt Lake City, UT, USA, 7-11 June 1993.

14. Ó Brádaigh, C.M.; Doyle, A.; Doyle, D.; Feerick, P.J. Electrically-Heated Ceramic Composite Tooling for Out-of-Autoclave Manufacturing of Large Composite Structures. SAMPE J. 2011, 47, 6-14. [CrossRef]

15. Flanagan, T.; Maguire, J.; Ó Brádaigh, C.M.; Mayorga, P.; Doyle, A. Smart Affordable Composite Blades for Tidal Energy. In Proceedings of the 11th European Wave and Tidal Energy Conference, Nantes, France, 6-11 September 2015; pp. 1-8.

16. Maguire, J.M.; Nayak, K.; Ó Brádaigh, C.M. Characterisation of epoxy powders for processing thick-section composite structures. Mater. Des. 2018, 139, 112-121. [CrossRef]

17. Maguire, J.M.; Simacek, P.; Advani, S.G.; Ó Brádaigh, C.M. Novel epoxy powder for manufacturing thick-section composite parts under vacuum-bag-only conditions. Part I: Through-thickness process modelling. Compos. Part A Appl. Sci. Manuf. 2020, 136, 105969. [CrossRef]

18. Maguire, J.M.; Nayak, K.; Ó Brádaigh, C.M. Novel epoxy powder for manufacturing thick-section composite parts under vacuum-bag-only conditions. Part II: Experimental validation and process investigations. Compos. Part A Appl. Sci. Manuf. 2020, 136, 105970. [CrossRef]

19. Floreani, C.; Cuthill, F.; Steynor, J.; Maguire, J.; Niessink, M.; Di Noi, S.; Wittevrongel, L.; McCarthy, E.; Flanagan, T.; Ó Brádaigh, C.M. Testing of a $6 \mathrm{~m}$ Hybrid Glass/Carbon Fibre Powder Epoxy Composite Wind Blade Demonstrator. In Proceedings of the SAMPE Europe 2020, Amsterdam, The Netherlands, 30 September-1 October 2020.

20. Robert, C.; Pecur, T.; Maguire, J.M.; Lafferty, A.D.; McCarthy, E.D.; Ó Brádaigh, C.M. A novel powder-epoxy towpregging line for wind and tidal turbine blades. Compos. Part B Eng. 2020, 203, 108443. [CrossRef]

21. Mamalis, D.; Flanagan, T.; Ó Brádaigh, C.M. Effect of fibre straightness and sizing in carbon fibre reinforced powder epoxy composites. Compos. Part A Appl. Sci. Manuf. 2018, 110, 93-105. [CrossRef]

22. Mamalis, D.; Murray, J.J.; McClements, J.; Tsikritsis, D.; Koutsos, V.; McCarthy, E.D.; Ó Brádaigh, C.M. Novel carbon-fibre powder-epoxy composites: Interface phenomena and interlaminar fracture behaviour. Compos. Part B Eng. 2019, $174,107012$. [CrossRef]

23. Blake, S.P.; Berube, K.A.; Lopez-Anido, R.A. Interlaminar fracture toughness of woven E-glass fabric composites. J. Compos. Mater. 2012, 46, 1583-1592. [CrossRef]

24. SAERTEX ${ }^{\circledR}$. U-C-603g/m²-1230mm Technical Datasheet; SAERTEX: Saerbeck, Germany, 2019.

25. SAERTEX ${ }^{\circledR}$. U-E-591 $\mathrm{g} / \mathrm{m}^{2}-1200 \mathrm{~mm}$ Technical Datasheet; SAERTEX: Saerbeck, Germany, 2019.

26. BS EN ISO 527-1:2019, Plastics: Determination of Tensile Properties. General Principles; Standard; International Organization for Standardization: Geneva, Switzerland, 2019.

27. Carlsson, L.A.; Adams, D.F.; Pipes, R.B. Experimental Characterization of Advanced Composite Materials; Taylor \& Francis Group: Abingdon, UK, 2014; pp. 149-168.

28. ASTM D6641/D6641M-16e1, Standard Test Method for Compressive Properties of Polymer Matrix Composite Materials Using a Combined Loading Compression (CLC) Test Fixture; Standard; ASTM International: West Conshohocken, PA, USA, 2016.

29. ASTM D5528-13, Standard Test Method for Mode I Interlaminar Fracture Toughness of Unidirectional Fiber-Reinforced Polymer Matrix Composites; Standard; ASTM International: West Conshohocken, PA, USA, 2013.

30. ASTM D6671, Standard Test Method for Mixed Mode I-Mode II Interlaminar Fracture Toughness of Unidirectional Fiber Reinforced Polymer Matrix Composites; Standard; ASTM International: Philadelphia, PA, USA, 2001.

31. Whitcomb, J.D. Analysis of Instability-Related Growth of a Through-Width Delamination; Tech. Memo 86301; NASA Langley Research Center: Hampton, VA, USA, 1984.

32. Benzeggagh, M.; Kenane, M. Measurement of mixed-mode delamination fracture toughness of unidirectional glass/epoxy composites with mixed-mode bending apparatus. Compos. Sci. Technol. 1996, 56, 439-449. [CrossRef]

33. ASTM D3171-15, Standard Test Methods for Constituent Content of Composite Materials; Standard; ASTM International: West Conshohocken, PA, USA, 2015. 
34. Frassine, R.; Rink, M.; Pavan, A. Viscoelastic effects on the interlaminar fracture behaviour of thermoplastic matrix composites: II. Rate and temperature dependence in unidirectional PEEK/carbon-fibre laminates. Compos. Sci. Technol. 1996, 56, 1253-1260. [CrossRef]

35. Alessi, S.; Pitarresi, G.; Spadaro, G. Effect of hydrothermal ageing on the thermal and delamination fracture behaviour of CFRP composites. Compos. Part B Eng. 2014, 67, 145-153. [CrossRef]

36. ZOLTEK Corporation. Zoltek ${ }^{T M}$ PX35 Uni-Directional Fabrics Technical Datasheet; ZOLTEK Corporation: Bridgeton, MO, USA, 2018.

37. Icten, B.M.; Atas, C.; Aktas, M.; Karakuzu, R. Low temperature effect on impact response of quasi-isotropic glass/epoxy laminated plates. Compos. Struct. 2009, 91, 318-323. [CrossRef]

38. Gopalakrishnan, M.; Muthu, S.; Subramanian, R.; Santhanakrishnan, R.; Karthigeyan, L. Tensile Properties Study of EGlass/Epoxy Laminate and $\pi / 4$ Quasi-Isotropic E-Glass/Epoxy Laminate. Polym. Polym. Compos. 2016, 24, 429-446. [CrossRef]

39. Ennis, B.L.; Kelley, C.L.; Naughton, B.T.; Norris, B.; Das, S.; Lee, D.; Miller, D. Optimized Carbon Fiber Composites in Wind Turbine Blade Design; Sandia Report, SAND2019-14173; Sandia National Lab.: Albuquerque, NM, USA, 2019.

40. Michno, M.J., Jr.; Shea, F.J. Tensile (Compressive) Properties of Glass-Epoxy Composites as a Function of Volume Fraction; Report AD-773 960; Monsanto Research Corporation: St. Louis, MO, USA, 1973.

41. Zweben, C. Composites: Overview. In Encyclopedia of Condensed Matter Physics; Bassani, F., Liedl, G.L., Wyder, P., Eds.; Elsevier: Oxford, UK, 2005; pp. 192-208. [CrossRef]

42. Argüelles, A.; Rocandio, C.; Rubiera, S.; Viña, I.; Viña, J. Influence of the Test Method on the Characterization of the Fatigue Delamination Behavior of a Composite Material under Mixed Mode I/II Fracture. Polymers 2019, 11, 1788. [CrossRef] [PubMed]

43. Bonhomme, J.; Argüelles, A.; Viña, J.; Viña, I. Fractography and failure mechanisms in static mode I and mode II delamination testing of unidirectional carbon reinforced composites. Polym. Test. 2009, 28, 612-617. [CrossRef]

44. Ducept, F.; Davies, P.; Gamby, D. Mixed mode failure criteria for a glass/epoxy composite and an adhesively bonded composite/composite joint. Int. J. Adhes. Adhes. 2000, 20, 233-244. [CrossRef]

45. Ghadami, F.; Dadfar, M.; Zeraati, A.S. Mixed mode I/II delamination analysis of rubber-modified glass-reinforced epoxy composites. J. Reinf. Plast. Compos. 2014, 33, 1634-1643. [CrossRef]

46. Shokrieh, M.; Zeinedini, A.; Ghoreishi, S. On the mixed mode I/II delamination R-curve of E-glass/epoxy laminated composites. Compos. Struct. 2017, 171, 19-31. [CrossRef]

47. Reeder, J. An Evaluation of Mixed-Mode Delamination Failure Criteria; NASA-TM-104210; Langley Research Center: Hampton, VA, USA, 1992.

48. Le Guen-Geffroy, A.; Davies, P.; Le Gac, P.Y.; Habert, B. Influence of Seawater Ageing on Fracture of Carbon Fiber Reinforced Epoxy Composites for Ocean Engineering. Oceans 2020, 1, 198-214. [CrossRef]

49. Pereira, A.; de Morais, A. Mixed mode I+II interlaminar fracture of carbon/epoxy laminates. Compos. Part A Appl. Sci. Manuf. 2008, 39, 322-333. [CrossRef]

50. LeBlanc, L.R.; LaPlante, G. Experimental investigation and finite element modeling of mixed-mode delamination in a moistureexposed carbon/epoxy composite. Compos. Part A Appl. Sci. Manuf. 2016, 81, 202-213. [CrossRef]

51. O'Brien, T.K. Composite Interlaminar Shear Fracture Toughness, GIIc: Shear Measurement or Sheer Myth? In Composite Materials: Fatigue and Fracture: 7th Volume; ASTM International: West Conshohocken, PA, USA, 1998; pp. 3-18. [CrossRef] 